\title{
Assistência de enfermagem no rastreamento do câncer de mama em pacientes atendidas na Unidade Básica de Saúde
}

Nursing assistance in the screening of breast cancer in patients seen at the Basic Health Unit Asistencia de enfermería en el cribado de cáncer de mama en pacientes atendidas en la Unidad Básica de Salud

Airton César Leite

ORCID: https://orcid.org/0000-0001-7184-8488 Centro Universitário Santo Agostinho, Brasil E-mail: ainton.cesar2014@gmail.com

Mariana Pereira Barbosa Silva ORCID: https://orcid.org/0000-0003-0852-8099 Universidade Estadual do Piauí, Brasil E-mail: marianapbsilvaa@gmail.com

Rayssa Stéfani Sousa Alves

ORCID: https://orcid.org/0000-0002-9666-675X Pontifícia Universidade Católica de Goiás, Brasil E-mail: rayssastefani02@gmail.com

Marciele de Lima Silva

ORCID: https://orcid.org/0000-0003-2827-5316

Instituto de Educação Superior da Paraíba, Brasil E-mail: marcieledelsilva@gmail.com

Danielle Sousa Almeida

ORCID: https://orcid.org/0000-0002-0537-8972

Centro Universitário Santo Agostinho, Brasil E-mail: daniellyalmeida99@gmail.com

Lorena Mayara Hipólito Feitosa ORCID: https://orcid.org/0000-0002-3643-3436 Universidade Federal do Piauí, Brasil E-mail: lorena_mayara@hotmail.com

Raimunda da Silva Sousa Neta ORCID: https://orcid.org/0000-0001-5927-0046 Centro Universitário Santo Agostinho, Brasil E-mail: raynettasousa@gmail.com

Nádia Domingas da Silva Santos ORCID: https://orcid.org/0000-0003-2325-6634 Centro Universitário Santo Agostinho, Brasil E-mail: nadiaumb@gmail.com

Maria Clara de Carvalho Freire Fernandes ORCID: https://orcid.org/0000-0002-4924-0457

Centro Universitário Santo Agostinho, Brasil E-mail: clarafernandesthe@gmail.com

Annarelly Morais Mendes ORCID: https://orcid.org/0000-0002-4367-8888

Universidade Estadual do Maranhão, Brasil E-mail: annarellymorais1@gmail.com

Bianca Barroso de Sousa

ORCID: https://orcid.org/0000-0002-3521-6667

Universidade Estadual do Maranhão, Brasil E-mail: biancabarroso000@gmail.com

Laiana Dias Prudêncio

ORCID: https://orcid.org/0000-0002-0016-3868

Centro Universitário UNINASSAU, Brasil

E-mail: laianadias568@gmail.com

Karla Cynthia dos Santos e Silva ORCID: https://orcid.org/0000-0003-4080-0048 Universidade Estadual da Paraíba, Brasil E-mail: kcynthia7283@gmail.com

Maria Carmilene Soares dos Santos ORCID: https://orcid.org/0000-0003-4030-0609 Associação Superior de Ensino, Brasil E-mail: soarescarmilene@gmail.com 


\author{
Maria dos Milagres Santos da Costa \\ ORCID: https://orcid.org/0000-0002-2290-5914 \\ Associação de Ensino Superior do Piauí, Brasil \\ E-mail: mariamsantos1010@gmail.com \\ Luiseunice Arraes Silva \\ ORCID: https://orcid.org/0000-0001-5998-820X \\ Faculdade NOVAUNESC, Brasil \\ E-mail: luise.arraes@hotmail.com \\ Juliana Torres Avelino \\ ORCID: https://orcid.org/0000-0002-8732-1856 \\ Centro Universitário Santo Agostinho, Brasil \\ E-mail: Juliana_avelinno@hotmail.com \\ Layanne Cavalcante de Moura \\ ORCID: https://orcid.org/0000-0003-2781-1076 \\ Centro Universitário UNIFACID, Brasil \\ E-mail: layannecavalcante@ hotmail.com \\ Renata Laís Lima Silva \\ ORCID: https://orcid.org/0000-0001-8428-4247 \\ Universidade Norte do Paraná, Brasil \\ E-mail: renata.lays45@gmail.com \\ Maria dos Santos Fernandes \\ ORCID: https://orcid.org/0000-0002-8746-6481 \\ Centro Universitário Doutor Leão Sampaio, Brasil \\ E-mail: mariafernandes9378@gmail.com \\ Cristina Lima dos Santos \\ ORCID: https://orcid.org/0000-0002-8863-6235 \\ Centro Universitário do Norte, Brasil \\ E-mail: limachrystina@gmail.com \\ Moacir Andrade Ribeiro Filho \\ ORCID: https://orcid.org/0000-0003-1991-469X \\ Universidade Regional do Cariri, Brasil \\ E-mail: moacirarf@outlook.com \\ Weberton Dorásio Sobrinho \\ ORCID: https://orcid.org/0000-0003-0619-7214 \\ Universidade de Rio Verde, Brasil \\ E-mail: dorasioweberton@gmail.com
}

\begin{abstract}
Resumo
Analisar as evidências científicas acerca da assistência de enfermagem no rastreamento do câncer de mama em pacientes atendidas na Unidade Básica de Saúde. O presente estudo trata de uma revisão bibliográfica do método revisão integrativa da literatura, realizado nos meses de outubro e novembro de 2020. A busca efetuou-se, através da BVS, utilizando as bases de dados (LILACS), (MEDLINE), (BDENF), e por meio do Portal Google Acadêmico, aderindo-se através dos descritores: "Cuidados de enfermagem" AND "Câncer de Mama" AND "Atenção Primária", combinados com o operador booleando "AND". É relevante que o enfermeiro desenvolva ações para o enfrentamento à neoplasia mamária, conheça os métodos de deteç̧ão precoce e realize ações de rastreamento para identificação antecedente do câncer de mama ou de lesões precursoras em indivíduos assintomáticos o mais rápido possível, para que sejam implementadas medidas efetivas reduzindo sua mortalidade. Os profissionais de saúde devem assumir a responsabilidade de participar na detecção de anormalidades na mama nas consultas realizando assim uma assistência integral, resolutiva e humanizada. Sendo fundamental a ação do enfermeiro durante as consultas na atenção à saúde da mulher na deteç̧ão destas anormalidades através do acolhimento, no exame clínico das mamas, na educação em saúde e solicitando exames mais complexos quando necessário.
\end{abstract}

Palavras-chave: Cuidados de enfermagem; Câncer de mama; Atenção Primaria.

\begin{abstract}
To analyze the scientific evidence about nursing care in the screening of breast cancer in patients seen at the Basic Health Unit. This study deals with a bibliographic review of the integrative literature review method, carried out in the months of October and November 2020. A The search was carried out through the VHL, using the databases (LILACS), (MEDLINE), (BDENF), and through the Google Scholar Portal, adhering to the descriptors: "Nursing care" AND "Cancer of Mama "AND" Primary Attention ", combined with the operator" B ". It is relevant that the nurse develops actions to face breast cancer, know the methods of early detection and perform screening actions for the previous identification of breast cancer or precursor lesions in asymptomatic individuals as soon as possible, so that effective measures are implemented reducing their mortality. Health professionals must assume the responsibility of participating in the detection of abnormalities in the breast in consultations, thus providing comprehensive, resolutive and humanized assistance. It is essential for nurses to act during consultations regarding women's health care in detecting these abnormalities through embracement, clinical breast examination, health education and requesting more complex tests when necessary.
\end{abstract}


Keywords: Nursing care; Cancer of mama; Primary attention.

\section{Resumen}

Analizar la evidencia científica sobre el cuidado de enfermería en el cribado de cáncer de mama en pacientes atendidas en la Unidad Básica de Salud. Este estudio trata de una revisión bibliográfica del método de revisión integradora de la literatura, realizada en los meses de octubre y noviembre de 2020. A La búsqueda se realizó a través de la BVS, utilizando las bases de datos (LILACS), (MEDLINE), (BDENF), y a través del Portal Google Scholar, adhiriéndose a los descriptores: "Nursing care" Y "Cancer of Mama "Y" Atención Primaria ", combinados con el operador" B ". Es relevante que la enfermera desarrolle acciones para enfrentar el cáncer de mama, conozca los métodos de detección precoz y realice acciones de cribado para la identificación previa de cáncer de mama o lesiones precursoras en individuos asintomáticos lo antes posible, para que se implementen medidas efectivas reduciendo su mortalidad. Los profesionales de la salud deben asumir la responsabilidad de participar en la detección de anomalías en la mama en las consultas, brindando así una asistencia integral, resolutiva y humanizada. Es fundamental que las enfermeras actúen durante las consultas relacionadas con el cuidado de la salud de la mujer en la detección de estas anomalías mediante el abrazo, el examen clínico de los senos, la educación sanitaria y la solicitud de pruebas más complejas cuando sea necesario.

Palabras clave: Cuidado de enfermera; Cáncer de mama; Atención primaria.

\section{Introdução}

O câncer de mama consiste em um tumor maligno que se desenvolve a partir da proliferação rápida e desordenada das células do órgão, podendo crescer nos tecidos circundantes ou se espalhar (metástase) para áreas distantes do corpo. Sua incidência é maior em países desenvolvidos, porém a sobrevida apresenta uma relação inversa com magnitude dos casos, de modo que, 69\% das mortes registradas pela doença são de países em desenvolvimento (Bushatsky et al., 2014).

O câncer de mama é a primeira causa de morte entre as mulheres. Mundialmente, esta neoplasia é o mais comum entre as mulheres, abrangendo $23 \%$ dos cânceres femininos que são diagnosticados em mais de 1,1 milhões de mulheres a cada ano. A mortalidade anual desta neoplasia é de mais de 411 mil mortes sendo responsável por mais de 1,6\% dos óbitos femininos por todas as causas, e o segundo tipo de câncer mais frequente no mundo. No Brasil, o câncer de mama também é o mais incidente entre as mulheres, correspondendo por $22 \%$ dos casos novos a cada ano (Zapponi, Tocantins, \& Vargens, 2015).

O câncer é reconhecido como um problema de saúde pública no Brasil desde 1919, entretanto, a partir de 1975, com a criação do Sistema de Informação de Mortalidade observou-se que, entre os cânceres no sexo feminino, o de mama já apresentava elevada prevalência e mortalidade no país. Sabe-se que esta doença, na maioria das vezes, cresce lentamente podendo ser diagnosticada na fase inicial pelo emprego de métodos isolados ou combinados de mamografia (MMG), exame clínico das mamas (ECM) e o incentivo ao autoexame das mamas (AEM) objetivando o cuidado corporal (Marques, Figueiredo, \& Gutiérrez, 2015).

Estudos sobre o câncer de mama revestem-se de relevância, pois trata-se de um dos cânceres mais frequentes entre as mulheres, tanto no Brasil quanto no mundo. Esse contexto alia-se ao fato de ser considerado um câncer de bom prognóstico se diagnosticado e tratado oportunamente. Entretanto, demanda ações integradas dos diferentes níveis de atenção à saúde para seu efetivo controle. A atenção primária, juntamente aos outros níveis de atenção à saúde, partilha a responsabilidade de buscar, permanentemente, a melhoria do acesso e da qualidade do atendimento à população, tendo um grande potencial de resolver parte significativa das queixas apresentadas pela demanda (Cavalcante, Silva, Marques, Figueiredo, \& Gutiérrez, 2013).

No que diz respeito às ações previstas pelas políticas públicas de saúde para o controle de câncer de mama na atenção primária, o enfermeiro tem um papel fundamental e encontra um amplo espaço para o desenvolvimento das atividades diárias, pois mantém considerável autonomia nas suas práticas. A ele são atribuídas as seguintes ações: realizar atendimento integral às mulheres; realizar consulta de enfermagem (coleta de exame preventivo e exame clínico das mamas, solicitar 
exames complementares e prescrever medicações, conforme protocolo ou outras normativas técnicas estabelecidas pelo gestor municipal, observadas as disposições legais da profissão); realizar atenção domiciliar, quando necessário; manter a disponibilidade de suprimentos; coordenar e supervisionar o trabalho dos agentes comunitários de saúde e da equipe de enfermagem (Cavalcante, Silva, Marques, Figueiredo, \& Gutiérrez, 2013).

Segundo Ferreira et al. (2020), a Atenção Primária à Saúde se configura como forma de ingresso preferencial do Sistema Único de Saúde e o elo entre toda a rede de atenção à saúde. Na APS ocorre o acolhimento aos usuários, promoção da vinculação e responsabilização entre usuários e profissionais de saúde, pois suas instalações circunjacentes à comunidade possibilitam o conhecimento da conjuntura social e o desenvolvimento de atividades de forma coletiva e individual.

A detecção precoce do câncer de mama é imprescindível para seu controle, principalmente, em decorrência das altas taxas de morbimortalidade e do diagnóstico tardio, presentes no Brasil. Essa medida tem como componentes o diagnóstico precoce e o rastreamento oportunístico ou organizado. Dessa forma, a atuação do enfermeiro para a detecção precoce do câncer de mama na a APS é fundamental para estimular a adesão da mulher, incluindo ações de promoção à saúde e até de tratamento e reabilitação, devendo ser aproveitadas as oportunidades em todos os atendimentos feitos nas Unidades Básicas de Saúde (UBS), o que poder potencializar seu papel de agente de mudanças, cuja ação guarda estreita proximidade com as usuárias (Teixeira, Goldman, Gonçalves, Gutiérrez, \& Figueiredo, 2017).

Nesse sentido, destacam-se, como atribuições do enfermeiro no controle do câncer de mama: realizar consulta de enfermagem; o ECM de acordo com a faixa etária e quadro clínico; examinar e avaliar sinais e sintomas relacionados à neoplasia; solicitar e avaliar exames de acordo com os protocolos locais; encaminhar e acompanhar nos serviços de referência para diagnóstico e/ou tratamento; realizar e participar das atividades de educação permanente (Teixeira, Goldman, Gonçalves, Gutiérrez, \& Figueiredo, 2017).

Segundo Mineo, Matos, Lima, Deluque, e Ferrari (2013), o câncer ainda é entendido pelas pessoas, em geral, como sinônimo de dor, morte e sofrimento. Nesta perspectiva, cabe à enfermagem identificar suas próprias concepções relativas ao câncer e estabelecer estratégias de enfrentamento, embasadas nas resoluções do COFEN 358/2009, 210/1998 e 211/1998 que os ampara, visando assim uma assistência adequada, humanizada e eficaz que possibilite minimizar o sofrimento de todos os envolvidos.

O câncer de mama por ser uma doença que apresenta diferentes situações de ameaça aos seus portadores pode trazer desconforto psicológico, o que gera ansiedade e um estado depressivo. Mudanças no seu estilo de vida causada por desconforto físico e pelo conceito de sua autoimagem podem levar a uma baixa estima, libido sexual diminuído, medo quanto ao sucesso do tratamento, assim como a possibilidade de sua recorrência e o temor da morte. A neoplasia mamária é um grande problema de saúde pública, pois a taxa de óbitos é alta, o gasto com o tratamento é grande, além de muitas vezes causar invalidez em pessoas produtivas para o mercado de trabalho (Mineo, Matos, Lima, Deluque, \& Ferrari, 2013).

A prevenção deve ser entendida como toda medida tomada para evitar o surgimento de uma condição mórbida ou de um conjunto seu, para que tal situação não ocorra na população, e se caso venha a ocorrer que se dê de forma mais leve. A prevenção do câncer de mama pode ser primária ou secundária, sendo a primária responsável por modificar ou eliminar fatores de risco para essa neoplasia; ao passo que na prevenção secundária enquadram-se o diagnóstico e o tratamento dos cânceres precoces. Destaca-se, porém, que a detecção precoce ainda é a melhor maneira de combater este tipo de câncer, pois só assim a doença adquire melhores chances de cura (Mineo, Matos, Lima, Deluque, \& Ferrari, 2013).

Tendo em vista da grande magnitude do câncer de mama em relação à saúde pública do Brasil e do mundo, a assistência de enfermagem a pacientes acometidos por tal patologia, deve ser estabelecida mediante as necessidades básicas de 
saúde dos mesmos. Assim, mediante a necessidade da detecção precoce, destacam que a atuação do enfermeiro na Atenção Primaria de Saúde é fundamental para estimular a adesão da mulher no tratamento (Pontes, Carvalho, Rocha, \& Batista, 2019).

Diante da problemática em discussão, surge como questão norteadora do estudo: "Qual a assistência de enfermagem no rastreamento do câncer de mama em pacientes atendidas na Unidade Básica de Saúde"?

A realização do estudo relacionado à temática, é essencial para a construção do conhecimento, pois, o estudo possibilita a sociedade acadêmica e cientifica a ampliar o conhecimento sobre a assistência de enfermagem no rastreamento do câncer de mama em pacientes atendidas na Unidade Básica de Saúde. A pesquisa aborda uma questão que deve ser bastante trabalhada e discutida pela equipe de saúde, no sentido de melhorar significativamente a assistência prestada a essas pacientes. Desse modo, o estudo trará contribuições significativas para a comunidade científica e para a sociedade, na medida em que acrescentará as evidências científicas discussões relevantes a respeito dessa temática.

Assim, o objetivo desse estudo é analisar as evidências científicas acerca da assistência de enfermagem no rastreamento do câncer de mama em pacientes atendidas na Unidade Básica de Saúde.

\section{Metodologia}

O presente estudo trata de uma revisão bibliográfica do método revisão integrativa da literatura, realizado nos meses de outubro e novembro de 2020. Sendo uma ferramenta de investigação que permite à procura, a avaliação crítica e a síntese das evidências disponíveis sobre o tema investigado, em que o produto final é o estado do conhecimento, a implementação de intervenções efetivas na prestação de cuidados e na redução de custos. Além disso, permite a identificação de fragilidades, que poderão conduzir ao desenvolvimento de futuras investigações (Sousa, Marques-Vieira, Severino, \& Antunes, 2017).

A revisão configura-se, portanto, como um tipo de revisão da literatura que reúne achados de estudos desenvolvidos mediante diferentes metodologias, permitindo aos revisores sintetizar resultados sem ferir a filiação epistemológica dos estudos empíricos incluídos. Para que esse processo concretize-se de maneira lógica, isenta de desatinos epistemológicos, a revisão requer que os revisores procedam à análise e à síntese dos dados primários de forma sistemática e rigorosa (Soares et al., 2014).

Esse instrumento de estudo requer um padrão de excelência quanto ao rigor metodológico para que seu produto possa trazer contribuições significativas para a ciência e para a prática clínica. A preservação deste padrão requer o uso de métodos que garantam a análise precisa, objetiva e completa do tema revisado; o suporte teórico para analisar resultados, métodos, sujeitos e variáveis dos estudos primários; a provisão de todas as informações contidas nos estudos revisados e não apenas os principais resultados, de modo a informar o leitor sem o sobrecarregar com informações desnecessárias (Soares et al., 2014).

O acompanhamento dos seguintes procedimentos, que devem ser desenvolvidos de forma crítica pelo revisor, foi sugerido: definir a questão ou o assunto da RI de forma clara; indicar hipóteses, que devem ser complementares à questão norteadora da revisão; descrever, de forma detalhada, os critérios de seleção dos estudos a serem incluídos na revisão; definir e descrever as características dos artigos analisados, etapa considerada núcleo da revisão integrativa (Soares et al., 2014). 
Fluxograma 1. Fases distintas da revisão integrativa.

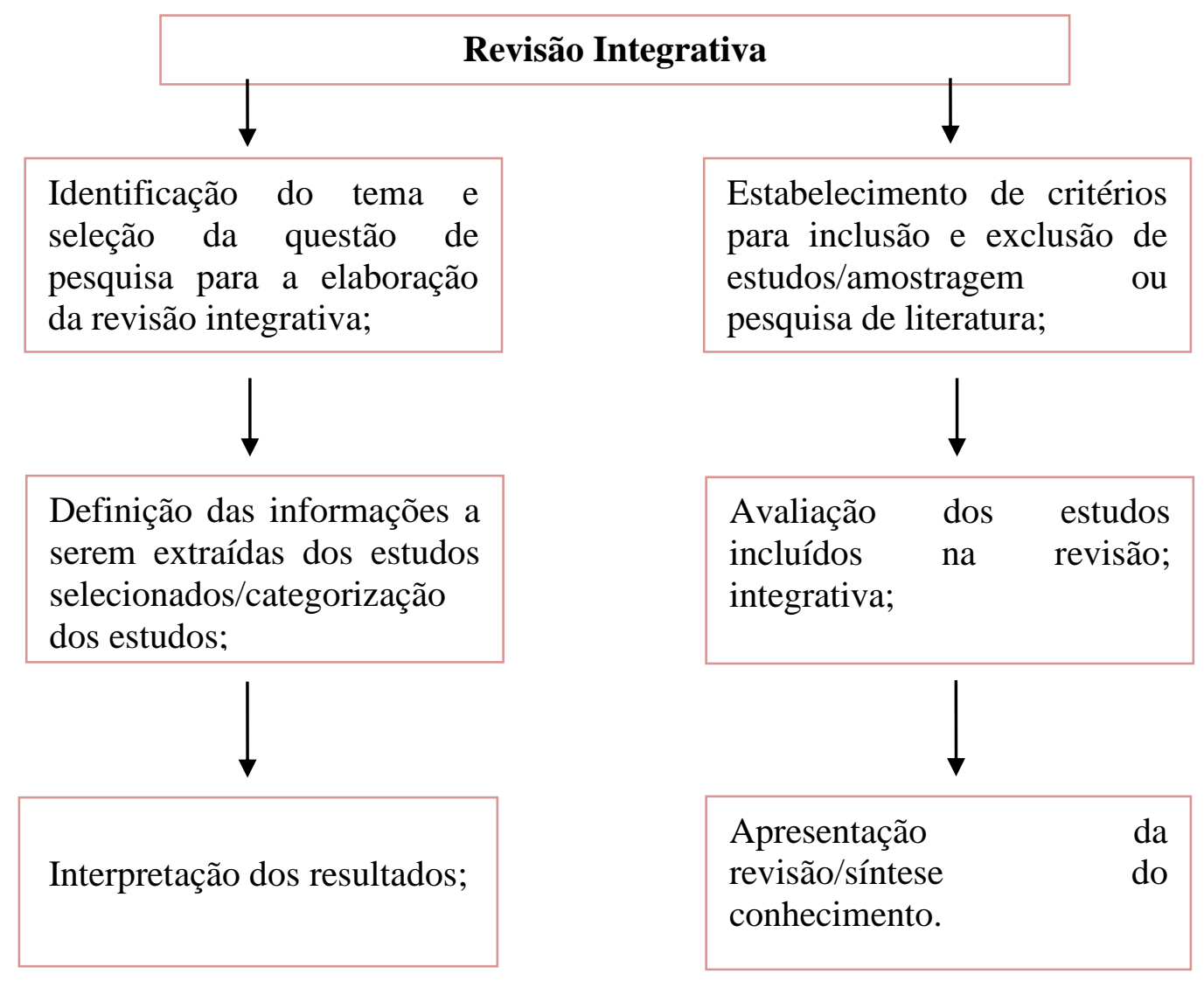

Fonte: Mendes, Silveira, \& Galvão (2008).

A revisão integrativa é um tipo de pesquisa que fornece informações mais amplas de maneira sistemática, ordenada e abrangente, sobre um assunto ou tema, com a finalidade de sintetizar resultados obtidos em pesquisa sobre temas ou questões. A definição das informações a serem extraídas dos estudos selecionados por categorização; avaliação dos estudos incluídos; interpretação dos resultados; e apresentação da revisão/síntese do conhecimento (Ercole, Melo, \& Alcoforado, 2015).

Estudo elaborado com abordagem qualitativa tornando-se importante a interpretação por parte do pesquisador com suas opiniões sobre o fenômeno em estudo. Neste tipo de pesquisa destacam-se algumas características como: a pesquisa qualitativa, em geral, ocorre no ambiente natural com coleta direta de dados e o pesquisador é o principal instrumento; os dados coletados são preferencialmente descritivos; a preocupação do processo é predominante em relação à do produto; a análise de dados e informações tende a seguir um processo indutivo. Dessa forma essa abordagem visa buscar o estudo de aspectos específicos, particulares, aplicado a grupos também específicos, com abordagem bastante ampla, e buscando saber como as pessoas veem e se sentem quando estão diante das situações estudadas. Aplicam métodos de investigação, enquetes e leitura (Pereira, Shitsuka, Parreira, \& Shitsuka, 2018).

De acordo com Souza, Silva e Carvalho (2010), a ser realizada nas seguintes etapas: 1- Elaboração da pergunta norteadora; 2- Busca nas bases de dados e amostragem; 3- Coleta de dados, 4- Análise crítica.

Utilizou-se para responder à questão norteadora do estudo: "Qual a assistência de enfermagem no rastreamento do câncer de mama em pacientes atendidas na Unidade Básica de Saúde”? os descritores/palavras chaves: "Cuidados de Enfermagem”, “Câncer de Mama”, “Atenção Primária”. 
A busca efetuou-se, através da Plataforma da Biblioteca Virtual em Saúde - BVS, utilizando as bases de dados Literatura Latino-Americana e do Caribe em Ciências da Saúde (LILACS), Medical Literature Analysis and Retrieval System Online (MEDLINE), Base de Dados de Enfermagem (BDENF), e por meio do Portal Google Acadêmico, aderindo-se através dos descritores: "Cuidados de enfermagem” AND "Câncer de Mama” AND “Atenção Primária”, combinados com o operador booleando “AND”.

Os critérios de inclusão estabelecidos foram: artigos originais disponibilizados na íntegra, completos, que abrangessem a temática e na forma online, publicados nos idiomas português, inglês e espanhol. Os critérios de exclusão estabelecidos na seleção foram: artigos incompletos, artigos duplicados, teses, dissertações, monografias e manuais. No início da pesquisa obteve-se 18815 publicações, após a aplicação dos critérios de inclusão e exclusão totalizou-se parcialmente 143 artigos, depois de uma leitura mais precisa aderiu-se um total final de 27 publicações de acordo para serem trabalhadas no estudo.

O presente fluxograma representado abaixo, caracteriza a estratégia de coleta de dados utilizada pelos autores, no sentido de detalhar as principais evidencias encontradas no estudo. 
Fluxograma 2. Estratégia de Busca. Teresina-PI, Brasil, 2020.

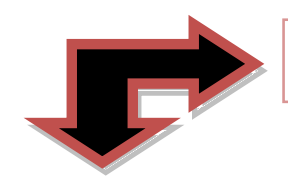

Outubro e Novembro de $\mathbf{2 0 2 0 .}$

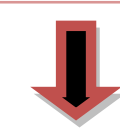

\section{Critérios de inclusão}

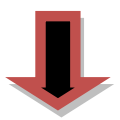

Artigos originais disponibilizados na íntegra, completos, que abrangessem a temática e na forma online, publicados nos idioma português, inglês e espanhol.

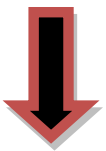

\section{Critérios de exclusão}

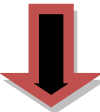

Artigos incompletos, artigos duplicados, teses, dissertações, monografias e manuais.
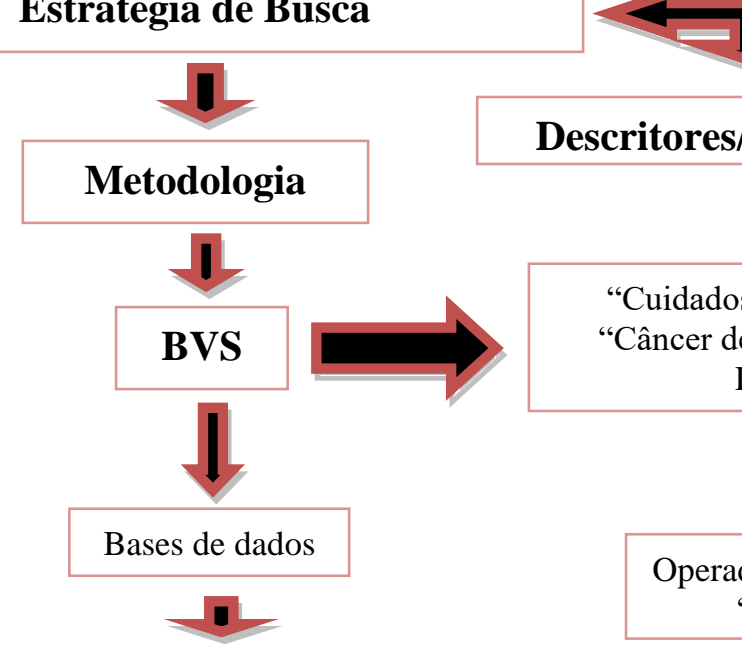

Descritores/Palavras chaves:

"Cuidados de Enfermagem",

"Câncer de Mama", "Atenção Primária”.

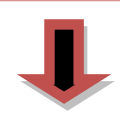

Operador booleano: "AND"

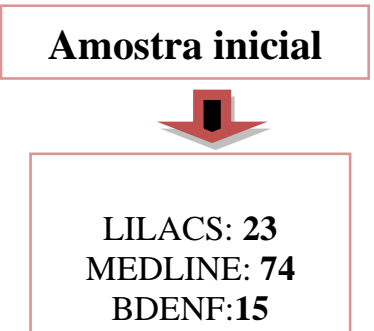

DENF:15

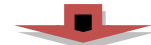

Google

Acadêmico: 18700

Amostra parcial

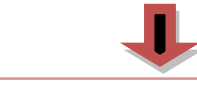

LILACS: 16

MEDLINE: 1

BDENF:15

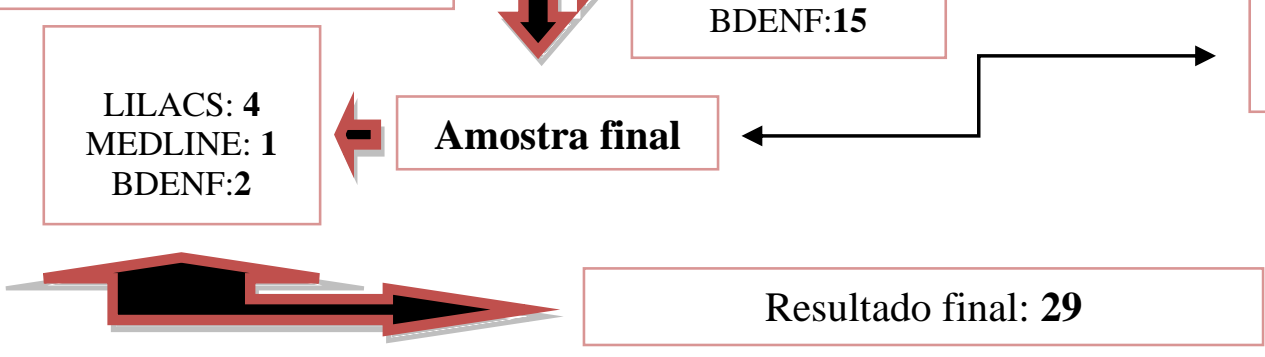

Fonte: Dados da pesquisa (2020).

No Fluxograma 2 estão expostos, estratégia de busca, bases de dados, período de realização do estudo, critérios de inclusão e exclusão, amostra inicial, parcial e final, de acordo com a quantidade de artigos que irão compor os resultados do estudo.

O presente estudo assegura os aspectos éticos, garantindo a autoria dos artigos pesquisados, utilizando para as citações e referências dos autores as normas APA. Os preceitos éticos estabelecidos no que se refere a zelar pela legitimidade das informações, privacidade e sigilo das informações, quando necessárias, tornando os resultados desta pesquisa públicos. Os pesquisadores buscaram a legitimidade e fidelidade nas citações dos autores seja nas citações diretas ou parafraseadas no estudo. 


\section{Resultados e Discussão}

Diante dos resultados obtidos no estudo por meio da estratégia de busca, os autores delinearam variáveis para melhor descrever as evidências encontradas na pesquisa. O quadro a seguir caracteriza os artigos com base nas variáveis propostas: número do artigo, periódico, base de dados, autor e ano de publicação, título, objetivo, resultados em evidências e conclusões importantes.

Quadro 1. Caracterização dos artigos conforme número, periódico, base de dados, título, objetivo, resultados em evidências e conclusões importantes. Teresina - PI, Brasil 2020.

\begin{tabular}{|c|c|c|c|c|c|c|}
\hline $\mathbf{N}$ & Periódico & $\begin{array}{c}\text { Bases de } \\
\text { dados }\end{array}$ & Título & $\begin{array}{c}\text { Autor e } \\
\text { ano }\end{array}$ & Objetivo & $\begin{array}{c}\text { Resultados em evidências } \\
\text { e } \\
\text { conclusões importantes }\end{array}$ \\
\hline 1 & $\begin{array}{l}\text { Rev Enferm } \\
\text { UERJ. }\end{array}$ & LILACS & $\begin{array}{l}\text { Ações do enfermeiro } \\
\text { na detecção precoce } \\
\text { do câncer mamário. }\end{array}$ & $\begin{array}{l}\text { Marques, } \\
\text { Silva, \& } \\
\text { Gutiérrez, } \\
2017 .\end{array}$ & $\begin{array}{l}\text { Analisar as ações dos } \\
\text { enfermeiros de } \\
\text { unidades básicas de } \\
\text { saúde (UBS) para a } \\
\text { detecção precoce do } \\
\text { câncer de mama, bem } \\
\text { como a estrutura } \\
\text { desses serviços. }\end{array}$ & $\begin{array}{l}\text { Para o controle desse agravo, } \\
\text { várias medidas inespecíficas de } \\
\text { prevenção primária vêm sendo } \\
\text { estimuladas, como a adoção do } \\
\text { estilo de vida saudável, o auto- } \\
\text { conhecimento corporal, o } \\
\text { controle de peso, a redução do } \\
\text { consumo de álcool e de tabaco. } \\
\text { Já as medidas específicas para } \\
\text { o controle do este tumor focam- } \\
\text { se no emprego de ações de } \\
\text { detecção precoce e na oferta de } \\
\text { tratamento oportuno. }\end{array}$ \\
\hline 2 & $\begin{array}{l}\text { Revista de } \\
\text { Saúde Pública } \\
\text { do Paraná. }\end{array}$ & LILACS & $\begin{array}{l}\text { Fatores que } \\
\text { influenciam ações } \\
\text { educativas sobre } \\
\text { câncer de mama na } \\
\text { Estratégia de Saúde } \\
\text { da Família. }\end{array}$ & $\begin{array}{l}\text { Mattos, } \\
\text { Silva, \& } \\
\text { Kölln, } \\
2016 .\end{array}$ & $\begin{array}{l}\text { Identificar fatores que } \\
\text { influenciam nas } \\
\text { atividades desenvolvi- } \\
\text { das pelo enfermeiro na } \\
\text { educação em saúde, } \\
\text { visando promoção à } \\
\text { saúde e prevenção do } \\
\text { câncer de mama. }\end{array}$ & $\begin{array}{l}\text { Os enfermeiros vivenciaram no } \\
\text { cotidiano de trabalho situações } \\
\text { que contribuíram para a } \\
\text { realização de atividades } \\
\text { voltadas para a prevenção do } \\
\text { câncer de mama como o } \\
\text { conhecimento prévio das } \\
\text { mulheres acerca do tema, bem } \\
\text { como o estabelecimento de um } \\
\text { acolhimento e vínculo. }\end{array}$ \\
\hline 3 & $\begin{array}{c}\text { Revista } \\
\text { Brasileira de } \\
\text { Cancerologia. }\end{array}$ & LILACS & $\begin{array}{lr}\text { Ações } & \text { do } \\
\text { Enfermeiro } & \text { no } \\
\text { rastreamento } & \text { e } \\
\text { Diagnóstico } & \text { do } \\
\text { Câncer de Mama no } \\
\text { Brasil. }\end{array}$ & $\begin{array}{c}\text { Cavalcante, } \\
\text { Silva, } \\
\text { Marques, } \\
\text { Figueiredo, } \\
\& \\
\text { Gutiérrez, } \\
2013 .\end{array}$ & $\begin{array}{l}\text { Identificar os estudos } \\
\text { referentes às ações } \\
\text { realizadas pelo } \\
\text { enfermeiro na atenção } \\
\text { primária para o } \\
\text { rastreamento } \\
\text { diagnóstico precoce do } \\
\text { câncer de mama no } \\
\text { Brasil. }\end{array}$ & $\begin{array}{l}\text { No que se refere à atenção } \\
\text { oncológica, o Ministério da } \\
\text { Saúde, por meio da Política } \\
\text { Nacional de Atenção } \\
\text { Oncológica, determina que as } \\
\text { intervenções para o controle de } \\
\text { câncer contemplem todos os } \\
\text { níveis de atenção e que a } \\
\text { assistência seja prestada por } \\
\text { equipe multidisciplinar, da qual } \\
\text { o enfermeiro é membro } \\
\text { integrante. }\end{array}$ \\
\hline 4 & $\begin{array}{l}\text { Rev. Enferm. } \\
\text { UERJ. }\end{array}$ & LILACS & $\begin{array}{l}\text { A detecção precoce } \\
\text { do câncer de mama } \\
\text { nor contexto } \\
\text { brasileiro. }\end{array}$ & $\begin{array}{l}\text { Zapponi, } \\
\text { Tocantins, } \\
\& \text { Vargens, } \\
2012 \text {. }\end{array}$ & $\begin{array}{l}\text { Identificar concepções } \\
\text { de detecção e } \\
\text { diagnóstico precoce de } \\
\text { câncer de mama } \\
\text { presente na literatura } \\
\text { científica. }\end{array}$ & $\begin{array}{l}\text { A concepção de detecção } \\
\text { precoce de câncer de mama } \\
\text { compreende a identificação de } \\
\text { alterações celulares no tecido } \\
\text { mamário de uma massa, } \\
\text { possível de ser detectado } \\
\text { através da palpação, enquanto } \\
\text { que o diagnóstico precoce } \\
\text { envolve a identificação. }\end{array}$ \\
\hline 5 & $\begin{array}{c}\text { Rev Esc } \\
\text { Enferm USP. }\end{array}$ & MEDLINE & $\begin{array}{lr}\text { Rastreamento opor- } \\
\text { tunístico do câncer } \\
\text { de } & \text { mama } \\
\text { desenvolvido por } & \text { permfermeiros rá da } \\
\text { entenção Primária à } \\
\text { Saúde. }\end{array}$ & $\begin{array}{l}\text { Moraes, } \\
\text { Almeida, } \\
\text { Figueiredo, } \\
\text { \& Loyola, } \\
\text { Panobianco } \\
\text {, } 2016 .\end{array}$ & $\begin{array}{l}\text { Identificar as ações de } \\
\text { rastreamento oportu- } \\
\text { nístico do câncer de } \\
\text { mama realizadas por } \\
\text { enfermeiros } \\
\text { unidades básicas de } \\
\text { saúde (UBS) de } \\
\text { Ribeirão Preto. }\end{array}$ & $\begin{array}{l}\text { Para que se possam adequar as } \\
\text { ações dos enfermeiros ao } \\
\text { rastreamento oportunístico do } \\
\text { câncer de mama são } \\
\text { necessários investimentos em } \\
\text { uma educação per manente } \\
\text { desses profissionais, assim } \\
\text { como em uma avaliação } \\
\text { contínua das ações de } \\
\text { rastreamento nas unidades de } \\
\text { saúde do município. }\end{array}$ \\
\hline
\end{tabular}




\begin{tabular}{|c|c|c|c|c|c|c|}
\hline 6 & $\begin{array}{l}\text { Rev Enferm } \\
\text { UERJ. }\end{array}$ & BDENF & $\begin{array}{l}\text { O enfermeiro na } \\
\text { detecção precoce do } \\
\text { câncer de mama no } \\
\text { âmbito da atenção } \\
\text { primária. }\end{array}$ & $\begin{array}{l}\text { Zapponi, } \\
\text { Tocantins, } \\
\text { \& Vargens, } \\
2015 .\end{array}$ & $\begin{array}{lr}\text { Identificar as ações } \\
\text { desenvolvidas pelos } \\
\text { enfermeiros na atenção } \\
\text { à saúde da mulher e } \\
\text { discutir a ação } \\
\text { profissional } & \text { do } \\
\text { enfermeiro } & \text { na } \\
\text { detecção precoce do } \\
\text { câncer de mama no } \\
\text { âmbito da atenção } \\
\text { primária. }\end{array}$ & $\begin{array}{l}\text { Os elevados índices de } \\
\text { incidência e mortalidade por } \\
\text { câncer de mama no Brasil } \\
\text { justificam a implantação de } \\
\text { estratégias efetivas de controle } \\
\text { dessa doença que incluam } \\
\text { ações de promoção à saúde, } \\
\text { prevenção e detecção precoce. }\end{array}$ \\
\hline 7 & $\begin{array}{l}\text { Rev Enferm } \\
\text { UERJ. }\end{array}$ & BDENF & $\begin{array}{l}\text { Políticas de saúde } \\
\text { pública para o } \\
\text { controle do câncer } \\
\text { de mama no Brasil. }\end{array}$ & $\begin{array}{c}\text { Marques, } \\
\text { Figueiredo, } \\
\& \\
\text { Gutiérrez, } \\
2015 .\end{array}$ & $\begin{array}{l}\text { Descrever as ações de } \\
\text { saúde pública para o } \\
\text { controle do câncer de } \\
\text { mama no Brasil. }\end{array}$ & $\begin{array}{l}\text { A diminuição de sequelas, } \\
\text { melhores } \\
\text { terapêuticas, bem como o } \\
\text { aumento da taxa de cura tem } \\
\text { sido observada em programas } \\
\text { de rastreamento sistemático, } \\
\text { respaldando assim, } \\
\text { formulação de ações de saúde } \\
\text { pública. }\end{array}$ \\
\hline 8 & $\begin{array}{l}\text { Acta Paul } \\
\text { Enferm. }\end{array}$ & $\begin{array}{l}\text { GOOGLE } \\
\text { ACADÊMI } \\
\text { CO }\end{array}$ & $\begin{array}{ll}\text { Atuação } & \text { do } \\
\text { enfermeiro } & \text { da } \\
\text { Atenção Primária no } \\
\text { controle do câncer } \\
\text { de mama. }\end{array}$ & $\begin{array}{c}\text { Teixeira, } \\
\text { Goldman, } \\
\text { Gonçalves, } \\
\text { Gutiérrez, } \\
\& \\
\text { Figueiredo, } \\
2017 .\end{array}$ & $\begin{array}{l}\text { Analisar as ações } \\
\text { realizadas } \\
\text { enfermeiros por } \\
\text { Atenção Primária em } \\
\text { Saúde da } \\
\text { rastreamento oportu- } \\
\text { nístico do câncer de } \\
\text { mama, tendo como } \\
\text { parâmetro a proposta } \\
\text { do Ministério da } \\
\text { Saúde. }\end{array}$ & $\begin{array}{l}\text { Os enfermeiros da ESF } \\
\text { executaram as ações de sua } \\
\text { competência, propostas pelo } \\
\text { Ministério da Saúde para o } \\
\text { rastreamento oportunístico do } \\
\text { câncer de mama. Entretanto, } \\
\text { algumas atividades não são de- } \\
\text { senvolvidas conforme } \\
\text { preconizado, como: faixa etária } \\
\text { e intervalo de tempo para } \\
\text { realização de exame clínico e } \\
\text { mamografia; busca ativa de } \\
\text { mulheres que faltaram à } \\
\text { mamografia; realização de } \\
\text { reunião educativa sobre o } \\
\text { câncer de mama. }\end{array}$ \\
\hline 9 & $\begin{array}{l}\text { Rev Enferm } \\
\text { UFPE online. }\end{array}$ & $\begin{array}{l}\text { GOOGLE } \\
\text { ACADÊMI } \\
\text { CO }\end{array}$ & $\begin{array}{l}\text { Câncer de mama: } \\
\text { ações de prevenção } \\
\text { na atenção primária } \\
\text { à saúde. }\end{array}$ & $\begin{array}{l}\text { Bushatsky } \\
\text { et al., } 2014 .\end{array}$ & $\begin{array}{l}\text { Identificar as ações de } \\
\text { prevenção do câncer } \\
\text { da mama feminina nas } \\
\text { áreas cobertas pelas } \\
\text { Unidades de Saúde da } \\
\text { Família. }\end{array}$ & $\begin{array}{l}\text { A neoplasia mamária quando } \\
\text { diagnosticada em estádios } \\
\text { iniciais tem percentuais mais } \\
\text { elevados de sobrevivência, } \\
\text { podendo chegar a } 100 \% \text { de cura } \\
\text { se tratada no estádio in situ. } \\
\text { Assim, a detecção através de } \\
\text { programas de rastreamento } \\
\text { representa uma alternativa que } \\
\text { favorece o diagnóstico em fases } \\
\text { iniciais da doença, o que } \\
\text { contribui para o tratamento } \\
\text { curativo e/ou maiores taxas de } \\
\text { sobrevida. }\end{array}$ \\
\hline 10 & $\begin{array}{l}\text { Revista } \\
\text { Eletrônica } \\
\text { Gestão \& } \\
\text { Saúde. }\end{array}$ & $\begin{array}{l}\text { GOOGLE } \\
\text { ACADÊMI } \\
\text { CO }\end{array}$ & $\begin{array}{l}\text { Assistência de } \\
\text { enfermagem no } \\
\text { tratamento do câncer } \\
\text { de mama. }\end{array}$ & $\begin{array}{l}\text { Mineo, } \\
\text { Matos, } \\
\text { Lima, } \\
\text { Deluque, \& } \\
\text { Ferrari, } \\
2013 .\end{array}$ & $\begin{array}{l}\text { Descrever a assistência } \\
\text { de enfermagem no } \\
\text { tratamento do câncer } \\
\text { de mama, visando à } \\
\text { assistência básica } \\
\text { antes, durante e após a } \\
\text { detecção do câncer. }\end{array}$ & $\begin{array}{l}\text { A utilização da SAE é usada } \\
\text { como recurso básico, mas a } \\
\text { enfermagem deve ir, além } \\
\text { disso, buscar uma assistência } \\
\text { que seja adequada e eficaz para } \\
\text { minimizar o sofrimento físico e } \\
\text { emocional de todos os } \\
\text { envolvidos no tratamento do } \\
\text { câncer de mama. }\end{array}$ \\
\hline 11 & $\begin{array}{l}\text { R. Enferm. } \\
\text { UFSM. }\end{array}$ & $\begin{array}{l}\text { GOOGLE } \\
\text { ACADÊMI } \\
\text { CO }\end{array}$ & $\begin{array}{l}\text { Artigo } \quad \text { original } \\
\text { mulheres mastecto- } \\
\text { mizadas: vivências } \\
\text { frente ao câncer de } \\
\text { mama. }\end{array}$ & $\begin{array}{l}\text { Mistura, } \\
\text { Carvalho, } \\
\text { \& Santos, } \\
2011 .\end{array}$ & $\begin{array}{l}\text { Identificar como as } \\
\text { mulheres mastectomi- } \\
\text { zadas enfrentam o } \\
\text { câncer e o tratamento } \\
\text { quimioterápico. }\end{array}$ & $\begin{array}{l}\text { O cuidado dispensado à mulher } \\
\text { deve ser realizado por uma } \\
\text { equipe multiprofissional, } \\
\text { assegurando uma assistência } \\
\text { integral, contemplando o ser } \\
\text { mulher em suas múltiplas } \\
\text { dimensões. }\end{array}$ \\
\hline 12 & $\begin{array}{l}\text { Rev Bras } \\
\text { Enferm. }\end{array}$ & $\begin{array}{l}\text { GOOGLE } \\
\text { ACADÊMI } \\
\text { CO }\end{array}$ & $\begin{array}{l}\text { Ações do enfermeiro } \\
\text { na detecção precoce } \\
\text { do câncer de mama. }\end{array}$ & $\begin{array}{c}\text { Melo, } \\
\text { Marques, } \\
\text { Rosa, } \\
\text { Figueiredo, } \\
\& \\
\text { Gutiérrez, } \\
2017 . \\
\end{array}$ & $\begin{array}{lr}\text { Identificar as ações de } \\
\text { detecção precoce do } \\
\text { câncer de mama } \\
\text { desenvolvidas } r \text { por } \\
\text { enfermeiros } & \text { de } \\
\text { Unidades Básicas de } & \text { de } \\
\text { Saúde. } & \\
\end{array}$ & $\begin{array}{l}\text { Destaca-se a influência positiva } \\
\text { da capacitação e tempo de } \\
\text { atuação na realização das ações } \\
\text { de detecção precoce do câncer } \\
\text { de mama e a necessidade de } \\
\text { ajustes para adequá-las às } \\
\text { diretrizes nacionais. }\end{array}$ \\
\hline
\end{tabular}




\begin{tabular}{|c|c|c|c|c|c|c|}
\hline 13 & $\begin{array}{c}\text { Escola Anna } \\
\text { Nery. }\end{array}$ & $\begin{array}{l}\text { GOOGLE } \\
\text { ACADÊMI } \\
\text { CO }\end{array}$ & $\begin{array}{l}\text { Conhecimento, ati- } \\
\text { tude e prática de } \\
\text { enfermeiros na } \\
\text { detecção do câncer } \\
\text { de mama. }\end{array}$ & $\begin{array}{l}\text { Ferreira et } \\
a l ., 2020 .\end{array}$ & $\begin{array}{l}\text { Analisar } \\
\text { conhecimento, as } \\
\text { práticas e atitudes } \\
\text { sobre a constatação de } \\
\text { câncer de mama por } \\
\text { profissionais enfermei- } \\
\text { ros da atenção } \\
\text { primária à saúde de } \\
\text { municípios do interior } \\
\text { do estado do Ceará, } \\
\text { Brasil. }\end{array}$ & $\begin{array}{l}\text { A educação permanente é um } \\
\text { ato estratégico, pois contempla } \\
\text { aspectos do pensar-fazer, } \\
\text { estimulando a reflexão e } \\
\text { criticidade dos profissionais na } \\
\text { sua prática, estimulando o } \\
\text { indivíduo a avaliar como estão } \\
\text { sendo realizadas as atividades, } \\
\text { onde precisa melhorar e a } \\
\text { responsabilidade de estar } \\
\text { executando-as para que se } \\
\text { tenham práticas com excelência } \\
\text { científica e técnica articulando } \\
\text { teoria e prática. }\end{array}$ \\
\hline 14 & $\begin{array}{c}\text { J. Res: } \\
\text { Fundam. } \\
\text { Care. Online. }\end{array}$ & $\begin{array}{l}\text { GOOGLE } \\
\text { ACADÊMI } \\
\text { CO }\end{array}$ & $\begin{array}{l}\text { Câncer de mama: } \\
\text { ações de prevenção } \\
\text { na estratégia de } \\
\text { saúde da família. }\end{array}$ & $\begin{array}{c}\text { Bushatsky } \\
\text { et al., } 2014 .\end{array}$ & $\begin{array}{l}\text { Levantar as ações de } \\
\text { prevenção ao câncer } \\
\text { de mama, segundo os } \\
\text { níveis estabelecidos } \\
\text { por Leavell \& Clarck, } \\
\text { na Estratégia Saúde da } \\
\text { Família de Sirinhaém } \\
\text { (PE). }\end{array}$ & $\begin{array}{l}\text { É importante agir em prol da } \\
\text { população feminina, com vista } \\
\text { em discussões a respeito das } \\
\text { questões que resultem em } \\
\text { possíveis tomadas de decisões e } \\
\text { estímulo no desenvolvimento } \\
\text { de práticas que assegurem a } \\
\text { adesão de um estilo de vida } \\
\text { mais saudável. Nessa linha de } \\
\text { pensamento, o enfermeiro } \\
\text { apresenta-se como uma peça } \\
\text { fundamental para o } \\
\text { desenvolvimento de práticas } \\
\text { educativas que corroborem } \\
\text { tanto na saúde individual } \\
\text { quanto coletiva, contribuindo } \\
\text { para a transformação da } \\
\text { realidade. }\end{array}$ \\
\hline 15 & $\begin{array}{l}\text { Revista JRG } \\
\text { de Estudos } \\
\text { Acadêmicos. }\end{array}$ & $\begin{array}{l}\text { GOOGLE } \\
\text { ACADÊMI } \\
\text { CO }\end{array}$ & $\begin{array}{l}\text { Ações de } \\
\text { enfermagem frente à } \\
\text { detecção precoce do } \\
\text { câncer de mama. }\end{array}$ & $\begin{array}{l}\text { Pontes, } \\
\text { Carvalho, } \\
\text { Rocha, \& } \\
\text { Batista, } \\
2019 .\end{array}$ & $\begin{array}{ll}\text { Descrever as ações de } \\
\text { enfermagem na } \\
\text { detecção precoce do } \\
\text { câncer de mama. }\end{array}$ & $\begin{array}{l}\text { As principais ações para a } \\
\text { detecção precoce do câncer de } \\
\text { mama, são: a educação em } \\
\text { saúde, o autoexame das mamas, } \\
\text { o exame clínico das mamas, a } \\
\text { prestação de serviço na } \\
\text { consulta de enfermagem e a } \\
\text { visita domiciliar a comunidade } \\
\text { sob risco de agravante. }\end{array}$ \\
\hline 16 & $\begin{array}{c}\text { Research, } \\
\text { Society and } \\
\text { Development. }\end{array}$ & $\begin{array}{l}\text { GOOGLE } \\
\text { ACADÊMI } \\
\text { CO }\end{array}$ & $\begin{array}{lr}\text { A educação } & \text { em } \\
\text { saúde } & \text { como } \\
\text { ferramenta } & \text { no } \\
\text { combate ao câncer } \\
\text { de mama. }\end{array}$ & $\begin{array}{c}\text { Costa et al., } \\
2020 .\end{array}$ & $\begin{array}{l}\text { Relatar uma ação de } \\
\text { educação em saúde } \\
\text { ocorrida no âmbito da } \\
\text { atenção primária de } \\
\text { saúde, cuja proposta } \\
\text { perpassava pela } \\
\text { prevenção do câncer } \\
\text { de mama a partir do } \\
\text { reconhecimento prévio } \\
\text { de suas manifestações, } \\
\text { bem domo da } \\
\text { manutenção de hábitos } \\
\text { saudáveis, visando a } \\
\text { promoção da saúde } \\
\text { dessas mulheres. }\end{array}$ & $\begin{array}{l}\text { No que tange aos profissionais } \\
\text { qualificados para o } \\
\text { desenvolvimento da educação } \\
\text { em saúde dentro dos serviços } \\
\text { assistenciais, destaca-se o } \\
\text { enfermeiro, posto que este } \\
\text { possui habilidades e } \\
\text { competências decorrentes de } \\
\text { sua formação que possibilitam } \\
\text { o estabelecimento de um } \\
\text { contato de confiança, a partir } \\
\text { de uma assistência holística e } \\
\text { equânime, voltada a } \\
\text { necessidades especificas, } \\
\text { auxiliando o usuário de } \\
\text { maneira longitudinal e } \\
\text { fomentando sua emancipação } \\
\text { nos processos de saúde-doença }\end{array}$ \\
\hline 17 & $\begin{array}{l}\text { REFACS } \\
\text { (online). }\end{array}$ & $\begin{array}{l}\text { GOOGLE } \\
\text { ACADÊMI } \\
\text { CO }\end{array}$ & $\begin{array}{lr}\text { Rastreamento } & \text { do } \\
\text { câncer de mama: } & \text { conhecimentos } \\
\text { práticas } & \text { de } \\
\text { trabalhadores } & \text { na } \\
\text { Unidade Básica de } & \text { daúde. } \\
\text { Saúl }\end{array}$ & $\begin{array}{l}\text { Sousa, } \\
\text { Carvalho, } \\
\& \text { Morais, } \\
2019 .\end{array}$ & $\begin{array}{l}\text { Desvelar os aspectos } \\
\text { que interatuam na } \\
\text { ocorrência do câncer } \\
\text { de mama, na } \\
\text { perspectiva } \\
\text { potencializar de } \\
\text { práticas preventivas. }\end{array}$ & $\begin{array}{l}\text { Os profissionais reconhecem a } \\
\text { importância do rastreamento na } \\
\text { prevenção e diagnóstico } \\
\text { precoce do câncer de mama, de } \\
\text { forma a contribuir para } \\
\text { tratamentos menos invasivos e } \\
\text { mutiladores. }\end{array}$ \\
\hline
\end{tabular}




\begin{tabular}{|c|c|c|c|c|c|c|}
\hline 18 & $\begin{array}{c}\text { Revista } \\
\text { Humano Ser } \\
\text { UNIFACEX. }\end{array}$ & $\begin{array}{l}\text { GOOGLE } \\
\text { ACADÊMI } \\
\text { CO }\end{array}$ & $\begin{array}{l}\text { O papel do } \\
\text { enfermeiro na } \\
\text { orientação, promo- } \\
\text { ção e prevenção do } \\
\text { câncer de mama. }\end{array}$ & $\begin{array}{l}\text { Cunha et } \\
\text { al., } 2018 .\end{array}$ & $\begin{array}{lr}\text { Descrever } & \text { a } \\
\text { importância } & \text { do } \\
\text { enfermeiro } & \text { na } \\
\text { orientação, } & \text { promoção } \\
\text { e prevenção do câncer } \\
\text { de mama. }\end{array}$ & $\begin{array}{l}\text { O enfermeiro é profissional } \\
\text { com atributos para promover, } \\
\text { prevenir e orientar os pacientes } \\
\text { nos serviços de saúde e na sua } \\
\text { comunidade, tendo participação } \\
\text { direta nos avanços do processo } \\
\text { de enfermagem, além do mais, } \\
\text { é possível endossar o } \\
\text { compromisso da prevenção } \\
\text { frente às doenças através de } \\
\text { palestras, oficinas e consulta de } \\
\text { enfermagem munida de } \\
\text { inovações para com às usuárias. }\end{array}$ \\
\hline 19 & Rev Rene. & $\begin{array}{l}\text { GOOGLE } \\
\text { ACADÊMI } \\
\text { CO }\end{array}$ & $\begin{array}{l}\text { Prevenção do câncer } \\
\text { de mama em } \\
\text { mulheres atendidas } \\
\text { em Unidade Básica } \\
\text { de Saúde. }\end{array}$ & $\begin{array}{l}\text { Arruda } e t \\
\text { al., } 2015 .\end{array}$ & $\begin{array}{l}\text { Descrever o perfil de } \\
\text { mulheres atendidas em } \\
\text { Unidade Básica de } \\
\text { Saúde e identificar as } \\
\text { atitudes relacionadas à } \\
\text { detecção precoce do } \\
\text { câncer de mama. }\end{array}$ & $\begin{array}{l}\text { Destaca-se a necessidade do } \\
\text { desenvolvimento } \\
\text { intervenções de } \\
\text { efetivas direcionadas aos } \\
\text { fatores de riscos e detecção } \\
\text { precoce do câncer de mama nos } \\
\text { serviços de saúde. }\end{array}$ \\
\hline 20 & $\begin{array}{c}\text { Portuguese } \\
\text { ReonFacema. }\end{array}$ & $\begin{array}{l}\text { GOOGLE } \\
\text { ACADÊMI } \\
\text { CO }\end{array}$ & \begin{tabular}{lc} 
Contribuições das & \multicolumn{2}{l}{ de } \\
características socio \\
-demográficas no \\
rastreamento & do \\
câncer de mama. &
\end{tabular} & $\begin{array}{l}\text { Nascimento } \\
\text { et al., } 2017 .\end{array}$ & $\begin{array}{l}\text { Analisar } r \\
\text { característic associo- } \\
\text { demográficas e suas } \\
\text { contribuições para o } \\
\text { rastreamento do câncer } \\
\text { de mama, para } \\
\text { prevenção e controle } \\
\text { dos índices de } \\
\text { morbimortalidade por } \\
\text { câncer de mama no } \\
\text { município de Caxias- } \\
\text { MA. }\end{array}$ & $\begin{array}{l}\text { A situação sociodemográfica } \\
\text { deixa essa população em estado } \\
\text { vulnerável para o } \\
\text { desenvolvimento de câncer de } \\
\text { mama. Portanto há necessidade } \\
\text { do fortalecimento aos serviços } \\
\text { de educação em saúde e ações } \\
\text { sociais para proporcionar e } \\
\text { garantir diagnóstico precoce } \\
\text { através do rastreamento e } \\
\text { consequentemente qualidade de } \\
\text { vida. }\end{array}$ \\
\hline 21 & Rev. APS. & $\begin{array}{l}\text { GOOGLE } \\
\text { ACADÊMI } \\
\text { CO }\end{array}$ & $\begin{array}{l}\text { O controle do câncer } \\
\text { de mama na atenção } \\
\text { primária: desafios na } \\
\text { elaboração do plano } \\
\text { amostral. }\end{array}$ & $\begin{array}{l}\text { Marques, } \\
\text { Figueiredo, } \\
\text { Gutiérrez, } \\
\& \\
\text { Cassenote, } \\
2014 .\end{array}$ & $\begin{array}{l}\text { Descrever } \\
\text { amostragem } \\
\text { identificar as ações no } \\
\text { controle do câncer de } \\
\text { mama na atenção } \\
\text { básica. }\end{array}$ & 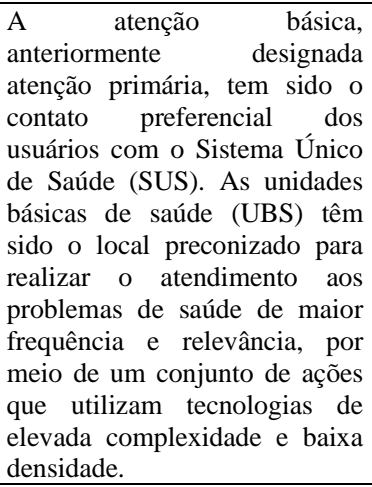 \\
\hline 22 & $\begin{array}{l}\text { Rev Enferm } \\
\text { UFPE Online. }\end{array}$ & $\begin{array}{l}\text { GOOGLE } \\
\text { ACADÊMI } \\
\text { CO }\end{array}$ & $\begin{array}{lr}\text { Orientações } & \text { de } \\
\text { cuidado } & \text { do } \\
\text { enfermeiro } & \text { para a } \\
\text { mulher } & \text { em } \\
\text { tratamento } & \text { para } \\
\text { câncer de mama. }\end{array}$ & $\begin{array}{l}\text { Ferrari et } \\
\text { al., } 2018 .\end{array}$ & $\begin{array}{l}\text { Identificar } \\
\text { principais queixas de } \\
\text { saúde que os } \\
\text { enfermeiros recebem } \\
\text { ao cuidar de mulheres } \\
\text { em tratamento } \\
\text { quimioterápico para } \\
\text { câncer de mama e } \\
\text { quais as principais } \\
\text { orientações de cuidado } \\
\text { são realizadas. }\end{array}$ & $\begin{array}{l}\text { Após o diagnóstico do câncer } \\
\text { de mama, a mulher passa por } \\
\text { fases, como o tratamento que } \\
\text { acarreta inúmeras mudanças, } \\
\text { sendo elas fisiológicas, sociais } \\
\text { e psicológicas. Embora os } \\
\text { avanços na área do tratamento } \\
\text { quimioterápico elevaram-se } \\
\text { positivamente, ainda há muito } \\
\text { para alcançar dentro de uma } \\
\text { linha conjunta entre o risco e } \\
\text { benefício para o paciente, como } \\
\text { por exemplo os efeitos } \\
\text { colaterais. }\end{array}$ \\
\hline 23 & $\begin{array}{c}\text { Revista } \\
\text { Extensão. }\end{array}$ & $\begin{array}{l}\text { GOOGLE } \\
\text { ACADEMMI } \\
\text { CO }\end{array}$ & $\begin{array}{l}\text { A importância da } \\
\text { educação em saúde } \\
\text { como forma de } \\
\text { prevenção ao câncer } \\
\text { de mama. }\end{array}$ & $\begin{array}{c}\text { Nunes, } \\
\text { Resende, } \\
\text { Cabral, } \\
\text { Oliveira, \& } \\
\text { Silva, 2020. }\end{array}$ & $\begin{array}{lr}\text { Contemplar } & \text { uma } \\
\text { perspectiva do ensino } \\
\text { em saúde que } \\
\text { ultrapassasse ras } \\
\text { barreiras da educação } \\
\text { tradicionalista a partir } \\
\text { da compreensão de } \\
\text { diferentes realidades } \\
\text { sociais. } \\
\end{array}$ & $\begin{array}{l}\text { A educação em saúde torna-se } \\
\text { fator primordial para a } \\
\text { ampliação do conhecimento } \\
\text { acerca das informações gerais } \\
\text { sobre câncer de mama, já que } \\
\text { possuem o escopo de promover } \\
\text { a prevenção, o estímulo ao } \\
\text { tratamento e o aumento da } \\
\text { sobrevida em mulheres. }\end{array}$ \\
\hline
\end{tabular}




\begin{tabular}{|c|c|c|c|c|c|c|}
\hline 24 & Rev Med. & $\begin{array}{l}\text { GOOGLE } \\
\text { ACADÊMI } \\
\text { CO }\end{array}$ & $\begin{array}{l}\text { O conhecimento de } \\
\text { mulheres acerca do } \\
\text { rastreamento do } \\
\text { câncer de mama e } \\
\text { suas implicações. }\end{array}$ & $\begin{array}{c}\text { Azevedo et } \\
\text { al., } 2019 .\end{array}$ & $\begin{array}{lr}\text { Analisar } & \text { o } \\
\text { conhecimento } & \text { de } \\
\text { mulheres entre } 35 \text { e } 69 \\
\text { anos cadastradas em } \\
\text { Estratégias de Saúde } \\
\text { da Família (ESF) de } \\
\text { Alfenas - MG acerca } \\
\text { do rastreamento do } \\
\text { câncer de mama. }\end{array}$ & $\begin{array}{l}\text { A realização de ações } \\
\text { preventivas que visam o } \\
\text { rastreamento e diagnóstico } \\
\text { precoce do câncer de mama } \\
\text { influencia diretamente na } \\
\text { redução da mortalidade e em } \\
\text { um melhor prognóstico da } \\
\text { doença. }\end{array}$ \\
\hline 25 & $\begin{array}{l}\text { Revista } \\
\text { Eletrônica } \\
\text { Acervo } \\
\text { Saúde. }\end{array}$ & $\begin{array}{l}\text { GOOGLE } \\
\text { ACADÊMI } \\
\text { CO }\end{array}$ & $\begin{array}{l}\text { Importância do } \\
\text { enfermeiro para o } \\
\text { controle do câncer } \\
\text { de mama. }\end{array}$ & $\begin{array}{l}\text { Rodrigues, } \\
\text { Salun, } \\
\text { Oliveira, } \\
\text { Lima, \& } \\
\text { Nunes, } \\
2020 .\end{array}$ & $\begin{array}{lr}\text { Verificar o papel do } \\
\text { enfermeiro } & \text { na } \\
\text { orientação } & \text { do } \\
\text { autoexame das mamas. }\end{array}$ & $\begin{array}{l}\text { O enfermeiro é visto como o } \\
\text { profissional principal e } \\
\text { responsável para ação do } \\
\text { controle do câncer de mama } \\
\text { através da realização de } \\
\text { educação para as mulheres com } \\
\text { orientações da importância da } \\
\text { realizção do autoexame das } \\
\text { mamas e enfatizando a } \\
\text { necessidade de observação de } \\
\text { sinais de alterações possíveis } \\
\text { nas mamas. }\end{array}$ \\
\hline 26 & $\begin{array}{c}\text { Research, } \\
\text { Society and } \\
\text { Development. }\end{array}$ & $\begin{array}{l}\text { GOOGLE } \\
\text { ACADÊMI } \\
\text { CO }\end{array}$ & $\begin{array}{lr}\text { O contexto } & \text { do } \\
\text { cuidar } & \text { em } \\
\text { enfermagem } & \text { a } \\
\text { mulheres } & \text { com } \\
\text { câncer de mama. } & \end{array}$ & $\begin{array}{c}\text { Sousa et } \\
\text { al., } 2020 .\end{array}$ & $\begin{array}{lr}\text { Compreender o } & \text { papel } \\
\text { do cuidado } \quad \text { em } \\
\text { enfermagem à paciente } \\
\text { acometidas } r \text { pela } \\
\text { neoplasia de } & \text { mama e } \\
\text { submetidas } & \text { a } \\
\text { mastectomia. } & \end{array}$ & $\begin{array}{l}\text { É preciso que o enfermeiro } \\
\text { esteja preparado para prestar } \\
\text { atendimento de qualidade. Faz- } \\
\text { se necessário mais estudos } \\
\text { sobre a temática para embasar a } \\
\text { identificação, descrição do } \\
\text { papel e preconizção de } \\
\text { políticas e programas que } \\
\text { possam melhor detalhar e } \\
\text { especificar a assistência de } \\
\text { enfermagem no diagnóstico } \\
\text { precoce ao câncer de mama e } \\
\text { pós mastectomia. }\end{array}$ \\
\hline 27 & $\begin{array}{c}\text { REFACS } \\
\text { (online). }\end{array}$ & $\begin{array}{l}\text { GOOGLE } \\
\text { ACADÊMI } \\
\text { CO }\end{array}$ & $\begin{array}{l}\text { Impacto da fadiga } \\
\text { na qualidade de vida } \\
\text { de mulheres com } \\
\text { câncer de mama. }\end{array}$ & $\begin{array}{l}\text { Campos et } \\
\text { al., } 2020 .\end{array}$ & $\begin{array}{l}\text { Avaliar a qualidade de } \\
\text { vida de mulheres com } \\
\text { fadiga secundária } \\
\text { quimioterapia durante } \\
\text { o tratamento para o } \\
\text { câncer de mama. }\end{array}$ & $\begin{array}{l}\text { A importância da atuação da } \\
\text { equipe multiprofissional em } \\
\text { buscar formas adequadas de } \\
\text { identificação, manejo e e } \\
\text { tratamento da fadiga, } \\
\text { juntamente com as pacientes e } \\
\text { seus cuidadores, além do } \\
\text { desenvolvimento de mais } \\
\text { estudos com esse grupo-com } \\
\text { mais avaliações ao longo do } \\
\text { tratamento - que visem } \\
\text { estabelecer de forma mais exata } \\
\text { o padrão de ocorrência da FSQ } \\
\text { e seu efeito ao longo do tempo. }\end{array}$ \\
\hline 28 & $\begin{array}{l}\text { Revista } \\
\text { Cadernos de } \\
\text { Medicina. }\end{array}$ & $\begin{array}{l}\text { GOOGLE } \\
\text { ACADÊMI } \\
\text { CO }\end{array}$ & $\begin{array}{l}\text { Fatores de risco e } \\
\text { prevenção do câncer } \\
\text { de mama. }\end{array}$ & $\begin{array}{l}\text { Oliveira et } \\
\text { al., } 2020 .\end{array}$ & $\begin{array}{lr}\text { Avaliar os fatores de } \\
\text { risco para o } \\
\text { desenvolvimento de } \\
\text { câncer de mama e a } \\
\text { importância } \\
\text { prevenção. }\end{array}$ & $\begin{array}{l}\text { A importância de se conhecer } \\
\text { os fatores de risco para câncer } \\
\text { de mama está relacionada não } \\
\text { só com fatores genéticos, mas } \\
\text { sim com um somatório de } \\
\text { fatores de risco, incluindo os } \\
\text { ambientais, onde quanto menos } \\
\text { exposição a mulher tiver a } \\
\text { fatores de risco para câncer de } \\
\text { mama, menores são as chances } \\
\text { do surgimento do câncer de } \\
\text { mama na mulher. }\end{array}$ \\
\hline 29 & $\begin{array}{l}\text { Saúde em } \\
\text { Revista. }\end{array}$ & $\begin{array}{l}\text { GOOGLE } \\
\text { ACADÊMI } \\
\text { CO }\end{array}$ & $\begin{array}{l}\text { Prevenção do câncer } \\
\text { de mama: } \\
\text { conhecimento de } \\
\text { mulheres de uma } \\
\text { unidade saúde da } \\
\text { família. }\end{array}$ & $\begin{array}{l}\text { Viegas et } \\
\text { al., } 2019 .\end{array}$ & $\begin{array}{l}\text { Apresentar } \quad \text { o } \\
\text { conhecimento de } \\
\text { mulheres participantes } \\
\text { de uma Unidade Saúde } \\
\text { da Família (USF) em } \\
\text { relação à prevenção } \\
\text { primária e secundária } \\
\text { do câncer de mama. }\end{array}$ & $\begin{array}{l}\text { A prevenção do câncer de } \\
\text { mama está atrelada } \\
\text { principalmente aos exames de } \\
\text { detecção precoce da doença, } \\
\text { como o autoexame, a } \\
\text { mamografia e o exame clínico } \\
\text { das mamas. Contudo, parte das } \\
\text { mulheres os cuidados para a } \\
\text { prevenção primária da doença. }\end{array}$ \\
\hline
\end{tabular}

Fonte: Dados da pesquisa (2020). 
No Quadro 1, tem-se a apresentação dos artigos selecionados para o estudo conforme número do artigo, periódico, base de dados, título, autor e ano, objetivo, resultados em evidências e conclusões importantes, com a finalidade de facilitar o desenvolvimento da discussão. A partir do estudo dos artigos estabeleceram-se discussões relevantes para observações das produções científicas relacionadas à pesquisa.

Gráfico 1. Distribuição dos artigos conforme periódico e quantidade de publicações.

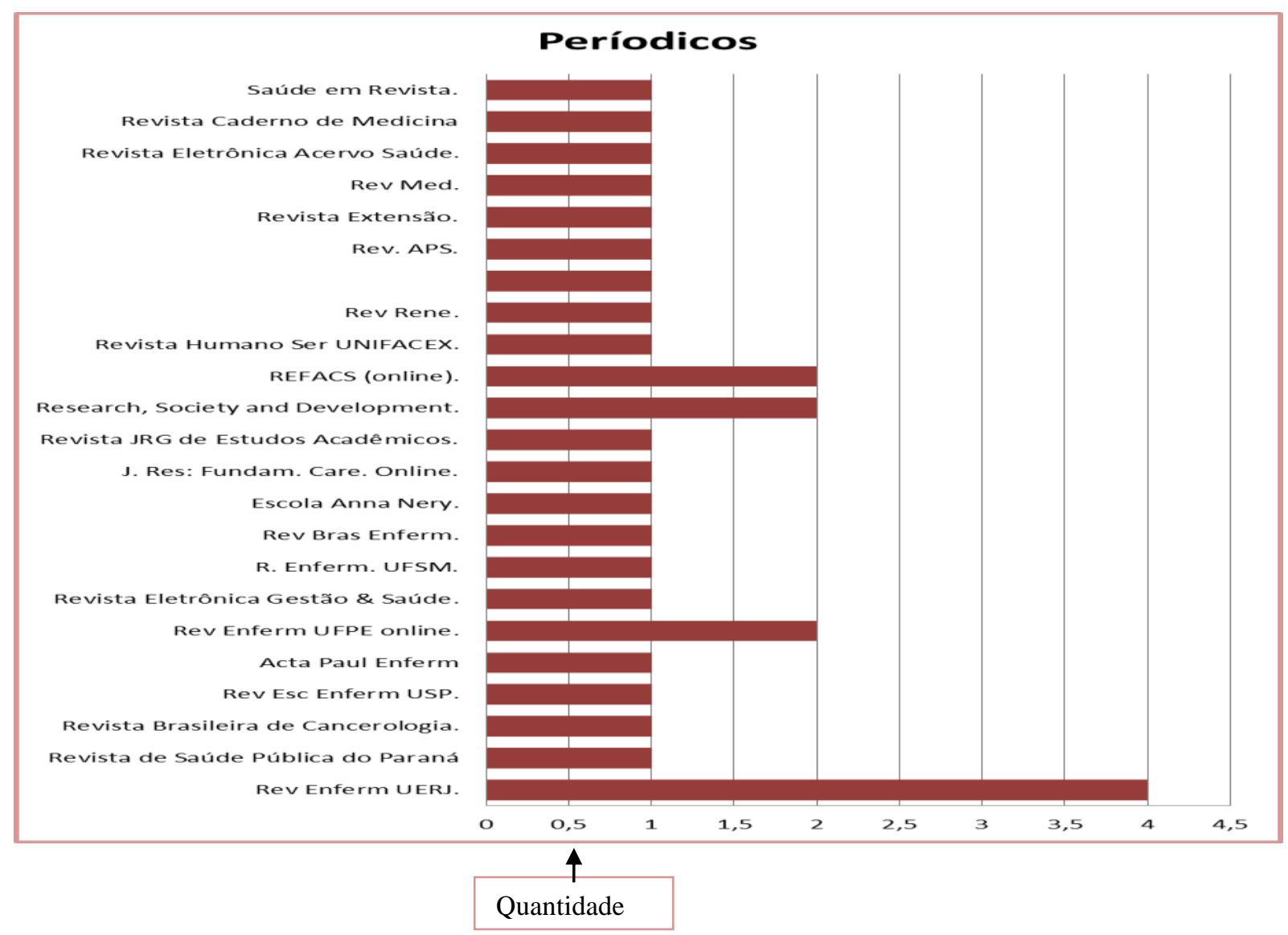

Fonte: Dados da pesquisa (2020).

De acordo com o gráfico acima observa-se os periódicos nos quais foram publicados os artigos da amostra final do presente estudo e sua quantidade, percebe-se que a Rev Enferm UERJ publicou (4) artigos, a Revista de Saúde Pública do Paraná (1), Revista Brasileira de Cardiologia (1), Rev Esc Enferm USP (1), Acta Paul Enferm (1), Rev Enferm UFPE Online (2), Revista Eletrônica Gestão \& Saúde (1), R. Enferm. UFSM (1), Rev Bras Enferm (1), Escola Anna Nery (1), J. Res. Fundam Care Online (1), Revista JRG de Estudos Acadêmicos (1), Research Society and Development (2), REFACS (online) (2), Revista Humano Ser UNIFACEX (1), Revista Rene (1), Portuguese Reon Facema (1), Rev APS (1), Revista Extensão (1), Rev Med (1), Revista Eletrônica Acervo Saúde (1), Revista Cadernos de Medicina (1), Saúde em Revista (1). Dessa forma, totalizando no geral 29 artigos para serem discutidos na construção do estudo. 
Gráfico 2. Distribuição da porcentagem de artigos encontrados de acordo com as bases de dados.

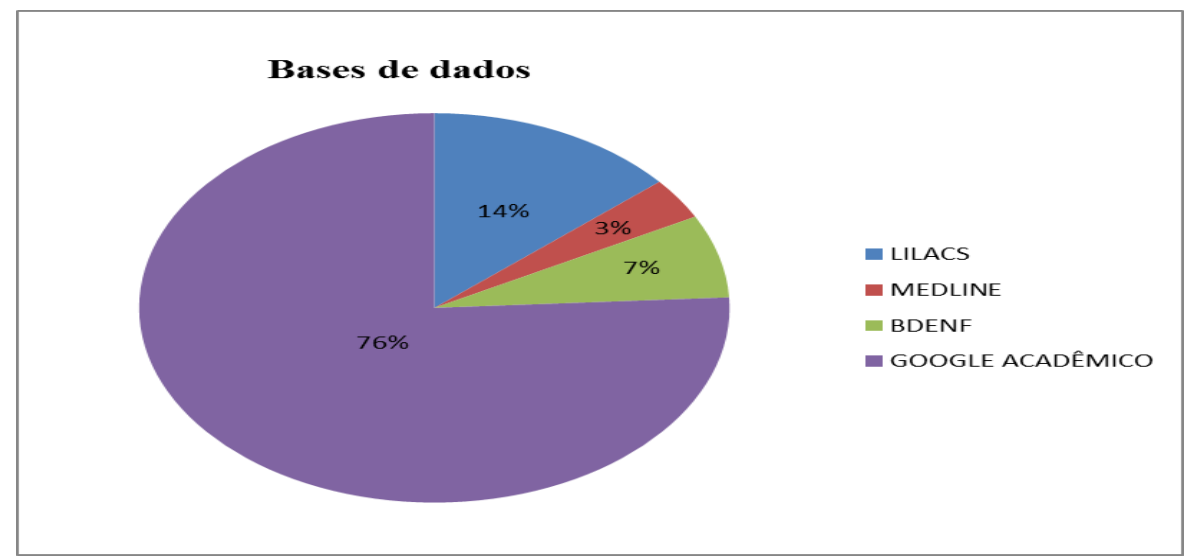

Fonte: Dados da pesquisa (2020).

Constata-se no gráfico acima que $14 \%$ dos artigos encontrados para compor a amostra do presente estudo foram indexados na base de dados da Literatura Latino-Americana e do Caribe em Ciências da Saúde (LILACS), 3\% Medical Literature Analysis and Retrieval System Online (MEDLINE), 7\% Base de Dados de Enfermagem (BDENF), e 76\% indexados no portal Google Acadêmico.

Gráfico 3. Distribuição dos artigos conforme ano de publicação e quantidade.

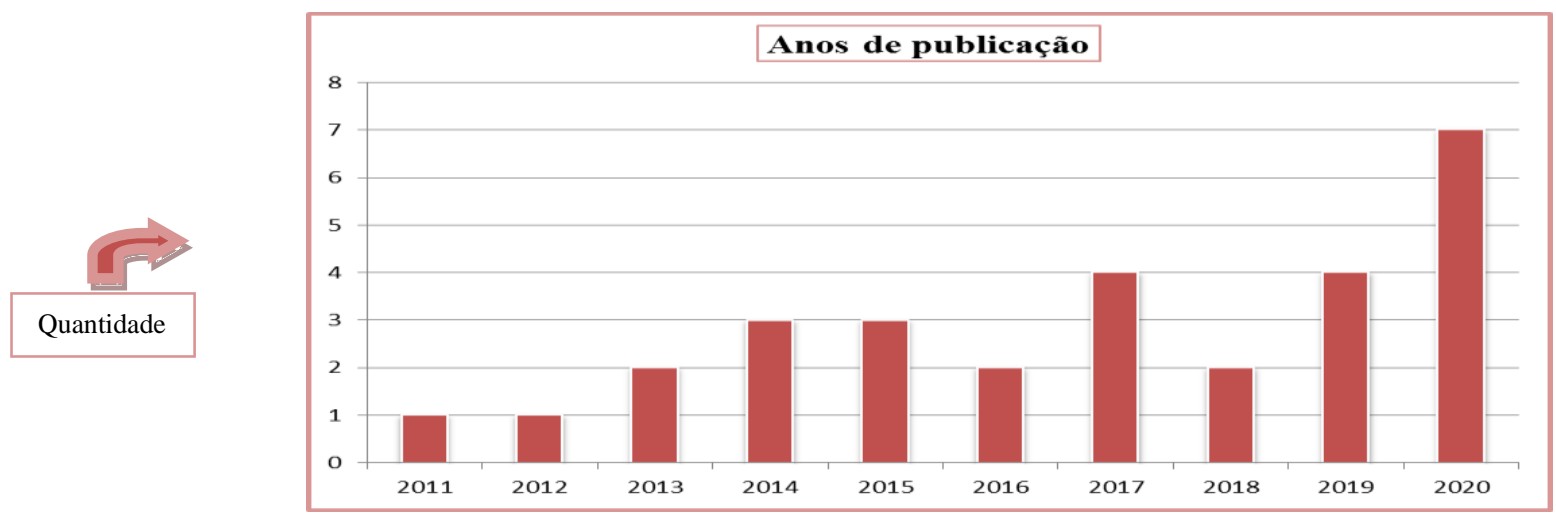

Fonte: Dados da pesquisa (2020).

Por meio do gráfico ilustrado acima, verifica-se que no ano de 2011 foi publicado (1) artigo, em 2012 (1), 2013 (2), 2014 (3), 2015 (3), 2016 (2), 2017 (4), 2018 (2), 2019 (4) e 2020 (7), chegando ao resultado final de 29 artigos para serem trabalhados na elaboração do presente estudo, sendo que foram seguidos criteriosamente os aspectos metodológicos de inclusão e exclusão abordado na referida pesquisa. 
Gráfico 4. Distribuição dos artigos conforme ano de publicação e porcentagem.

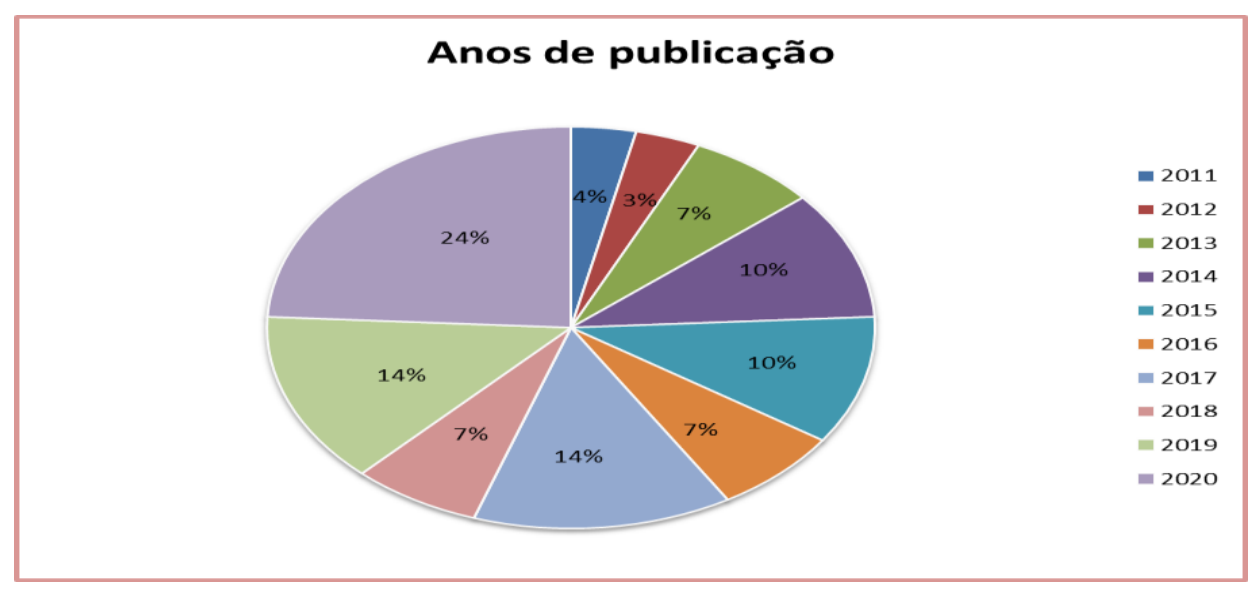

Fonte: Dados da pesquisa (2020).

Diante do gráfico acima percebe-se que no ano de 2011 foi publicado 4\% da amostra final do estudo, em 2012 (3\%), 2013 (7\%), 2014 (10\%), 2015 (10\%), 2016 (7\%), 2017 (14\%), 2018 (7\%), 2019 (14\%), e 2020 (24\%), aderindo o resultado final de 29 (100\%) publicações para compôr a amostra final utilizada na construção do presente estudo.

O câncer de mama, é o segundo mais comum em relação aos sítios de localização, com uma incidência de 1,7 milhões de novos casos, ou 11,9\% de todos os cânceres. Ocupa a quinta posição como causa de morte por câncer, com 522.000 ou $6,4 \%$ das mortes, por ter um prognóstico relativamente favorável. Dessa forma, para o controle desta neoplasia, são fundamentais as ações de rastreamento, que consistem na realização sistemática e periódica de exames em mulheres assintomáticas, bem como a detecção precoce para mulheres sintomáticas com vistas ao diagnóstico em estágios iniciais, quando os tratamentos são considerados mais eficientes e são maiores as chances de cura da doença (Moraes, Almeida, Figueiredo, Loyola, \& Panobianco, 2016).

Nesse sentido, é evidente a importância dessa neoplasia no contexto das políticas públicas de saúde, com destaque para a necessidade de capacitação dos profissionais, organização dos serviços de saúde e ações educativas às usuárias. Investimentos em ações de prevenção, detecção precoce e implementação de programas efetivos no controle da doença são apontados como medidas fundamentais (Moraes, Almeida, Figueiredo, Loyola, \& Panobianco, 2016).

O câncer de mama é considerado uma das principais causas de morbimortalidade da população feminina, cuja crescente incidência está diretamente relacionada aos fatores de risco como o envelhecimento, fatores relacionados à vida reprodutiva da mulher, história familiar de câncer de mama, consumo de álcool, excesso de peso, sedentarismo e exposição à radiação. O câncer de mama é a maior causa de morte por câncer nas mulheres em todo o mundo, pois é uma doença que possui comportamentos distintos, podendo ser observada pelas variadas manifestações clínicas e morfológicas, diferentes assinaturas genéticas e consequentes diferenças nas respostas terapêuticas (Mattos, Silva, \& Kölln, 2016).

Os principais sinais e sintomas que podem fornecer indícios da presença do câncer de mama são: presença de nódulo, geralmente endurecido, fixo e indolor na região das mamas; pele mamária avermelhada e com aspecto de casca de laranja; alterações no formato do mamilo; saída espontânea de líquido sanguinolento ou amarelado pelos mamilos. Além disso, pode ocorrer também nódulos nas axilas e na região do pescoço devido ao inchaço dos linfonodos (Nunes, Resende, Cabral, Oliveira, \& Silva, 2020).

Segundo Mattos, Silva, e Kölln (2016), as estratégias que compreendem a prevenção e controle do câncer de mama têm como objetivos reduzir a incidência, a mortalidade e as repercussões físicas, psíquicas e sociais causadas pelo seu 
adoecimento, por meio de ações de prevenção, oferta de serviços para detecção em estágios iniciais da doença e para o tratamento e reabilitação das mulheres.

Nesse sentido, é fundamental que os profissionais de saúde conheçam as políticas de atenção à saúde da mulher e, dentre esses profissionais, o enfermeiro que deve garantir o atendimento integral à saúde da mulher em todas as fases da vida por meio de ações preventivas que causam impacto positivo na diminuição das doenças, principalmente o câncer de mama. Por sua vez, a participação do enfermeiro nesse grupo contribui na sensibilização dos problemas das mulheres, garantindo a promoção e prevenção do câncer de mama, além de humanizar o atendimento à população feminina (Mattos, Silva, \& Kölln, 2016).

Assim, na Estratégia de Saúde da Família (ESF) tem-se uma possibilidade efetiva de realizar, de forma integral, a promoção à saúde e prevenção do câncer de mama. Para tanto, o profissional enfermeiro, membro da Equipe de Saúde da Família, tem por atividades realizar assistência integral às pessoas e famílias e, ainda, como atribuições, desenvolver atividades educativas, por meio de ações individuais e/ou coletivas com todas as pessoas da comunidade, realizando assim, promoção e proteção à saúde em todas as fases do desenvolvimento humano. Ademais, sendo o enfermeiro o profissional da equipe de saúde que possui um contato efetivo com o usuário, ele desempenha um papel fundamental nas ações de promoção à saúde e prevenção das doenças, incorporando na sua prática cotidiana ações voltadas para a educação em saúde abordando o controle do câncer de mama, tornando sua atitude positiva sobre a prática e o ensino do mesmo, o que constitui um elemento facilitador na atividade de educação em saúde e diminuição da taxa de mortalidade (Mattos, Silva, \& Kölln, 2016).

Desse modo, a Atenção Básica (AB), cenário estruturante para o desenvolvimento de várias ações no controle da neoplasia mamária maligna, constitui-se na porta de entrada do usuário nos serviços de saúde, caracteriza-se como um local privilegiado para a realização de ações educativas. Nesse aspecto, os profissionais da AB têm um papel fundamental no desenvolvimento dessas ações, especialmente o enfermeiro, considerado o principal articulador entre a equipe de saúde e os usuários dos serviços (Moraes, Almeida, Figueiredo, Loyola, \& Panobianco, 2016).

Nesse contexto, a detecção precoce do câncer de mama faz-se mais presente e acessível ao usuário do que o diagnóstico precoce. Considerando a importância de ambas as estratégias para a redução da morbimortalidade do câncer de mama, deve-se atentar para que os profissionais de saúde não percam de vista o propósito das tecnologias de acordo com a realidade social do país. Dessa forma, sugere-se que cada profissional de saúde assuma na sua prática assistencial a responsabilidade de participar na detecção precoce de anormalidades na mama como recurso equitativo da saúde como direito (Zapponi, Tocantins, \& Vargens, 2012).

O suporte familiar encoraja a mulher na lutar contra o câncer, fortalecendo as carências emocionais e aumentando a aceitação. É uma das principais formas de estratégias acionadas para o enfrentamento da neoplasia. A família desempenha um papel importante frente ao diagnóstico de câncer, representando um ponto de apoio fundamental e positiva para as tomadas de decisões. Os laços afetivos que normalmente une seus membros é um fator de aproximação, de ajuda física, emocional e cuidado à mulher. O envolvimento de todos contribui para uma recuperação mais rápida e menos traumática (Mistura, Carvalho, \& Santos, 2011).

Ressaltam-se as iniciativas para a reorganização da Atenção Primária à Saúde (APS), no sentido de reafirmar o fortalecimento das ações de promoção da saúde e prevenção de agravos e doenças, por meio da universalização do acesso à saúde e da descentralização do sistema. Nesse nível de atenção, o enfermeiro encontra um amplo espaço para o desenvolvimento de suas atividades, pois mantém considerável autonomia nas suas práticas, com participação efetiva nos processos educativos, nos movimentos de organização social, bem como na liderança de funções estratégicas de cunho gerencial (Melo, Marques, Rosa, Figueiredo, \& Gutiérrez, 2017). 
É necessário que profissionais da saúde, em especial os enfermeiros, tenham o conhecimento destas informações para que possam atuar na prevenção desta doença e promoção da saúde com uma visão integrada nos diferentes níveis de atenção à saúde, atendendo o indivíduo na sua integralidade, com enfoque do desenvolvimento das suas ações na atenção primária à saúde. A Atenção Primária à Saúde (APS) se configura como forma de ingresso preferencial do Sistema Único de Saúde e o elo entre toda a rede de atenção à saúde. Na APS ocorre o acolhimento aos usuários, promoção da vinculação e responsabilização entre usuários e profissionais de saúde, pois suas instalações circunjacentes à comunidade possibilitam o conhecimento da conjuntura social e o desenvolvimento de atividades de forma coletiva e individual (Ferreira et al., 2020).

É relevante que o enfermeiro desenvolva ações para o enfrentamento à neoplasia mamária, conheça os métodos de detecção precoce e realize ações de rastreamento para identificação antecedente do câncer de mama ou de lesões precursoras em indivíduos assintomáticos o mais rápido possível, para que sejam implementadas medidas efetivas reduzindo sua mortalidade (Ferreira et al., 2020).

Assim, assistência de enfermagem nos cuidados constituem inúmeros esforços para auxiliar as pacientes, nos quais os enfermeiros, além dos cuidados terapêuticos, os cuidados oncológicos para superação dos problemas requerem um tratamento longo, sendo possível de evitar efeitos adversos. Cabe, portanto, ao enfermeiro fornecer orientações de cuidados como identificar efeitos colaterais e minimizá-los (Pontes, Carvalho, Rocha, \& Batista, 2019).

Para a deteç̧ão precoce do câncer de mama, é recomendado um rastreamento a partir do exame clínico da mama, seguido por mamografia. Programas de detecção precoce são fundamentais para a detecção de agravos relacionados à mama, $\mathrm{e}$ qualquer alteração detectada é considerada um bom prognóstico quando tratada precocemente. O rastreamento do câncer de mama deve ser feito pelo profissional enfermeiro através das consultas de enfermagem, onde se deve fazer uma anamnese e um exame físico detalhado, orientando o público alvo, sobre o autoexame que deve ser realizado nas próprias residências, e se preciso, solicitar exames complementares (Pontes, Carvalho, Rocha, \& Batista, 2019).

O profissional da saúde, em casos específicos, precisa se dispor a ir até as comunidades, através de visitas domiciliares e comunitárias, onde ele estará orientando as mulheres sobre os cuidados e os possíveis fatores de risco que acarreta está doença. É diante destas ações, para o rastreamento do câncer de mama na atenção básica de saúde, que o enfermeiro poderá atuar na detecção precoce de um possível quadro clinico da doença. Desta forma, profissional da saúde presta um papel fundamental no rastreamento e detecção precoce do câncer mamário, o qual, é parte integrante da equipe multiprofissional e deve atual no âmbito da comunicação, prestação de informaç̃os, coordenação e manutenção de dados. Suas ações permeiam a identificação do público alvo, treinamento profissional, além do desenvolvimento de atividades que objetivem e incentivem a adesão das mulheres ao exame mamográfico como principal modo de rastreio (Pontes, Carvalho, Rocha, \& Batista, 2019).

Dentre os profissionais de saúde envolvidos no cuidado à mulher com câncer de mama, o enfermeiro é aquele que se destaca, por prestar cuidados durante todos os estágios da doença, seja no diagnóstico, durante o tratamento e na sua alta hospitalar. As intervenções e a prática de cuidados dos enfermeiros devem ser prestadas de forma que a paciente seja assistida integralmente, sendo necessário que o profissional tenha o conhecimento técnico-cientifico da sua área de cuidado (Ferrari et al., 2018).

O enfermeiro é aquele que atua desde a atenção básica prestando orientações, como a realização do Autoexame de Mama (AEM), ECM e mamografia, como formas de prevenção. E é quem passa, também, a orientar o paciente durante o tratamento quimioterápico sobre seus efeitos adversos, sendo essencial para esclarecer dúvidas dos pacientes e instruí-los sobre a forma correta de autocuidado. As orientações realizadas pelos enfermeiros aos pacientes em tratamento quimioterápico podem auxiliar na promoção do autocuidado e são de suma importância para que eles compreendam que também podem assumir sua responsabilidade no tratamento (Ferrari et al., 2018). 
A equipe de enfermagem tem papel fundamental na prevenção pois são eles que orientam os pacientes na prevenção primária relacionado aos melhores hábitos de vida. O enfermeiro tem o dever de educador, principalmente no cenário da atenção primária onde possui capacitação e autonomia para realizar campanhas, palestras e solicitar exames e medicar devido o respaldo dos protocolos institucionais existentes. O papel do enfermeiro torna-se imprescindível para colocar em prática as estratégias para diagnosticar a doença precocemente, diminuindo assim casos de câncer que são descobertos de forma tardia (Rodrigues, Salun, Oliveira, Lima, \& Nunes, 2020).

Levando-se em conta o papel essencial do enfermeiro na prevenção e controle desta enfermidade, percebemos que suas condutas vão desde a realização da consulta de enfermagem e orientação de seus pacientes de exames necessários e participação em ações educativas, exercendo assim, além de um papel preventivo, um aliado no diagnóstico precoce da patologia. Nesse contexto, os enfermeiros devem estar capacitados e trabalhar com uma equipe multidisciplinar para enfrentar esse desafio, além de humanizar e melhorar o atendimento à mulher. É necessário que durante a consulta de enfermagem esse profissional transmita informações adequadas sobre a importância da alimentação saudável, prática de atividade física, autoexame para conhecimento do corpo e do exame clínico com periodicidade, importância para realização da mamografia assim como a periodicidade recomendada para o rastreamento, mesmo sem achados clínicos significativos (Rodrigues, Salun, Oliveira, Lima, \& Nunes, 2020).

A enfermagem participa ativamente de todo o processo desses cuidados, visto que é a categoria profissional que tem a possibilidade de estar mais próximo do paciente e da família. Não é preciso apenas habilidades técnicas, mais que isso, é preciso ter sensibilidade e ser capaz de envolver a todos de forma positiva, estar disposto ao diálogo, respeitar a liberdade e a vontade de cada um, e conseguir reconhecer a dignidade do ser humano nas circunstâncias mais adversas (Sousa et al., 2020).

\section{Conclusão}

Evidenciou-se no estudo que, as ações dos profissionais de enfermagem constituem mais do que necessárias para que haja a detecção precoce desta neoplasia. Os profissionais de saúde devem assumir a responsabilidade de participar na detecção de anormalidades na mama nas consultas realizando assim uma assistência integral, resolutiva e humanizada. Sendo fundamental a ação do enfermeiro durante as consultas na Atenção à Saúde da Mulher na detecção destas anormalidades através do acolhimento, no exame clínico das mamas, na educação em saúde e solicitando exames mais complexos quando necessário tendo consciência que os cuidados a mulheres não devem estar somente no outubro rosa.

Entende-se que, essa neoplasia ocasiona muitas fragilidades para as mulheres acometidas, por diversos fatores, principalmente pelo fato de uma das modalidades terapêuticas para este tipo de câncer ser a cirurgia de mastectomia considerada ainda como o principal recurso para melhorar, controlar e erradicar a doença. Mas, este tipo de procedimento por si só tem um caráter agressivo e traumatizante para a vida e saúde das pacientes, fato este que está diretamente ligado a imagem corporal, ocasionando limitações físicos, preconceitos, transtornos emocionais, sociais em muitos casos associado à depressão e ansiedade.

Nesse contexto, verifica-se como é importante o enfoque da prevenção primária na ESF em relação a educar as mulheres para a realização de exames periódicos que permitam o diagnóstico precoce do câncer de mama, doença esta responsável pela morte de inúmeras mulheres brasileiras que deixaram a saúde ginecológica de lado. Dessa forma, torna-se importante a realização de estudos futuros, no intuito de obter uma maior compreensão acerca dessa patologia tão agressiva, e que proporcione a construção de evidências científicas que tragam discussões relevantes sobre essa temática. 


\section{Referências}

Arruda, R. L., Teles, E. D., Machado, N. S., de Oliveira, F. J. F., Fontoura, I. G., \& Ferreira, A. G. N. (2015). Prevenção do câncer de mama em mulheres atendidas em Unidade Básica de Saúde. Revista da Rede de Enfermagem do Nordeste, 16(2), 143-149.

Azevedo, A., Ramos, A. L., Gonçalves, A. C. V., de Souza, C. F., Batista, G. S., Silva, R. B. V., \& de Loyola, E. A. C. (2019). O conhecimento de mulheres acerca do rastreamento do câncer de mama e suas implicações. Revista de Medicina, 98(3), 187-193.

Bushatsky, M., Barros, M. B. S. C., da Rocha Cabral, L., da Rocha Cabral, J., da Silva Bezerra, J. R., \& dos Santos Figueira Filho, A. S. (2014). Câncer de mama: ações de prevenção na estratégia de saúde da família. Revista de Pesquisa Cuidado é Fundamental Online, 6(2), 663-675.

Bushatsky, M., Lima, K. D., Moraes, L. X., Gusmão, L. T. B., Barros, M. B. S. C., \& Figueira Filho, A. S. S. (2014). Câncer de mama: ações de prevenção na atenção primária à saúde. Rev enferm UFPE, 8(10), 3429-36.

Campos, C. S., Oliveira, T. D. S. G., dos Anjos, A. C. Y., Ferreira, M. B. G., Magnabosco, P., \& Porto, J. P. (2020). Impacto da fadiga na qualidade de vida de mulheres com câncer de mama. Revista Família, Ciclos de Vida e Saúde no Contexto Social, 8(3), 383-391.

Cavalcante, S. D. A. M., da Silva, F. B., Marques, C. A. V., de Figueiredo, E. N., \& de Gutiérrez, M. G. R. (2013). Ações do Enfermeiro no rastreamento e Diagnóstico do Câncer de Mama no Brasil. Revista Brasileira de Cancerologia, 59(3), 459-466.

Costa Viegas, A., Muniz, R. M., Cardoso, D. H., dos Santos, B. P., Machado, J. B., \& Lindemann, L. G. (2019). Prevenção do câncer de mama: conhecimento de mulheres de uma unidade saúde da família. Saúde em Revista, 19(51), 57-76.

Costa, P. V. D. P., da Silva, J. M. L., da Silva, L. C., Rocha, S. G., da Costa, L. F., Soares, M. K. M., \& da Silva Soeiro, J. (2020). A educação em saúde como ferramenta no combate ao câncer de mama. Research, Society and Development, 9(10), e6389108912-e6389108912.

Cunha, A. R., de Almeida, A. A., Oliveira, S. P. S., Paulino, T. S. C., Junior, L. S. D. S., \& Fontinele, D. C. S. D. S. (2018). O papel do enfermeiro na orientação, promoção e prevenção do câncer de mama. Revista Humano Ser, 3(1).

Ercole, F. F., Melo, L. D., \& Alcoforado, C. L. G. C. (2014). Revisão integrativa versus revisão sistemática Rev Min Enferm, 18(1), 9-12.

Ferrari, C. F., Abreu, E. C. D., Trigueiro, T. H., Silva, M. B. G. M. D., Kochla, K. A., \& Souza, S. R. R. K. (2018). Orientações de cuidado do enfermeiro para a mulher em tratamento para câncer de mama. Rev. enferm. UFPE on line, 676-683.

Ferreira, D. D. S., Bernardo, F. M. D. S., Costa, E. C., Maciel, N. D. S., Costa, R. L. D., \& Carvalho, C. M. D. L. (2020). Conhecimento, atitude e prática de enfermeiros na detecção do câncer de mama. Escola Anna Nery, 24(2).

Marques, C. A. V., da Silva, V. R., \& Gutiérrez, M. G. R. (2017). Ações do enfermeiro na detecção precoce do câncer mamário [Nurses’ role in early detection of breast cancer][Acciones del enfermero en la detección temprana del cáncer de mama]. Revista Enfermagem UERJ, $25,22639$.

Marques, C. A. V., de Figueiredo, E. N., de Gutiérrez, M. G. R., \& Cassenote, A. J. F. (2014). O controle do câncer de mama na atenção primária: desafios na elaboração do plano amostral. Revista de APS, 17(2).

Marques, C. A. V., de Gutiérrez, M. G. R., \& de Figueiredo, E. N. (2015). Políticas de saúde pública para o controle do câncer de mama no Brasil. Revista Enfermagem UERJ, 23(2), 272-278.

Mattos, M. D., Silva, K. L. D., \& Kõlln, W. M. (2016). Fatores que influenciam ações educativas sobre câncer de mama na Estratégia de Saúde da Família. Espaç. Saúde (Online), 40-48.

Melo, F. B. B., Marques, C. A. V., Rosa, A. D. S., Figueiredo, E. N. D., \& Gutiérrez, M. G. R. D. (2017). Ações do enfermeiro na detecção precoce do câncer de mama. Revista Brasileira de Enfermagem, 70(6), 1119-1128.

Mendes, K. D. S., Silveira, R. C. D. C. P., \& Galvão, C. M. (2008). Revisão integrativa: método de pesquisa para a incorporação de evidên cias na saúde e na enfermagem. Texto \& contexto enfermagem, 17(4), 758-764.

Mineo, F. V., Matos, L. D. F. B., da Silva Lima, S., Deluque, A. L., \& Ferrari, R. (2013). Assistência de enfermagem no tratamento do câncer de mama. Gestão e Saúde, 4(2), 2238-2260.

Mistura, C., Carvalho, M. D. F. A. A., \& Santos, V. E. P. (2011). Mulheres mastectomizadas: vivências frente ao câncer de mama. Revista de Enfermagem da UFSM, 1(3), 351-359.

Moraes, D. C., de Almeida, A. M., de Figueiredo, E. N., de Loyola, E. A. C., \& Panobianco, M. S. (2016). Rastreamento oportunístico do câncer de mama desenvolvido por enfermeiros da Atenção Primária à Saúde. Revista da Escola de Enfermagem da USP, 50(1), 14-21.

Nascimento, S. P., Pessoa, R. M. C., Silva, A., de Sousa, R. S., \& dos Santos, M. B. L. (2017). Contribuições das características sociodemográficas no rastreamento do Câncer de Mama. Revista Ciência \& Saberes-UniFacema, 3(2), 483-488.

Nunes, V. L. S., de Resende, W. A., Cabral, G. V. S., Oliveira, F. D. S. R., \& dos Santos Silva, R. R. (2020). A importância da educação em saúde como forma de prevenção ao câncer de mama: um relato de experiência em uma unidade básica de saúde de Palmas/TO. Revista Extensão, 4(2), 108-114.

Oliveira, A. L. R., Michelini, F. S., Spada, F. C., Pires, K. G., de Oliveira Costa, L., de Figueiredo, S. B. C., \& Lemos, A. (2020). Fatores de risco e prevenção do câncer de mama. Cadernos da Medicina-UNIFESO, 2(3).

Pereira, A. S., Shitsuka, D. M., Parreira, F. J., \& Shitsuka, R. (2018). Metodologia da pesquisa científica. 
Research, Society and Development, v. 10, n. 1, e8510111464, 2021

(CC BY 4.0) | ISSN 2525-3409 | DOI: http://dx.doi.org/10.33448/rsd-v10i1.11464

Pontes, D. S., Carvalho, J. S. M., Rocha, L. S., \& Batista, M. H. J. (2019). Ações de enfermagem frente à detecção precoce do câncer de mama. Revista JRG de Estudos Acadêmicos, 2 (5).

Rodrigues, J. R. G., Salun, A. A. L. A., de Oliveira, V. A. S. C., de Lima, P. B., \& Nunes, M. R. (2020). Importância do enfermeiro para o controle do câncer de mama: revisão narrativa. Revista Eletrônica Acervo Saúde, (55), e3668-e3668.

Soares, C. B., Hoga, L. A. K., Peduzzi, M., Sangaleti, C., Yonekura, T., \& Silva, D. R. A. D. (2014). Revisão integrativa: conceitos e métodos utilizados na enfermagem. Revista da Escola de Enfermagem da USP, 48(2), 335-345.

Sousa, C. N. S., de Carvalho, J. B. L., \& Morais, F. R. R. (2019). Rastreamento do câncer de mama: conhecimentos e práticas de trabalhadores na Unidade Básica de Saúde. Revista Família, Ciclos de Vida e Saúde no Contexto Social, 7(3), 306-312.

Sousa, L. M. M., Marques-Vieira, C. M. A., Severino, S. S. P., \& Antunes, A. V. (2017). A metodologia de revisão integrativa da literatura em enfermagem. No21 Série 2-Novembro 2017, 17.

Sousa, L. T. L., de Castro Alencar, A. A., Santos, M. C., de Souza, F. E. X., Uzumaki, K. D. L. R., dos Santos Silva, B. M., \& da Silva Martins, V. H. (2020). O contexto do cuidar em enfermagem a mulheres com câncer de mama. Research, Society and Development, 9(8), e926986231-e926986231.

Souza Teixeira, M., Goldman, R. E., Gonçalves, V. C. S., de Gutiérrez, M. G. R., \& de Figueiredo, E. N. (2017). Atuação do enfermeiro da Atenção Primária no controle do câncer de mama. Acta Paulista de Enfermagem, 30(1), 1-7.

Souza, M. T. D., Silva, M. D. D., \& Carvalho, R. D. (2010). Revisão integrativa: o que é e como fazer. Einstein (São Paulo), 8(1), 102-106.

Zapponi, A. L. B., Tocantins, F. R., \& da Costa Vargens, O. M. (2012). A detecção precoce do câncer de mama no contexto brasileiro. Revista Enfermagem UERJ, 20(3), 386-390.

Zapponi, A. L. B., Tocantins, F. R., \& Vargens, O. M. D. C. (2015). O enfermeiro na detecção precoce do câncer de mama no âmbito da atenção primária. Rev. enferm. UERJ, 23(1), 33-38. 